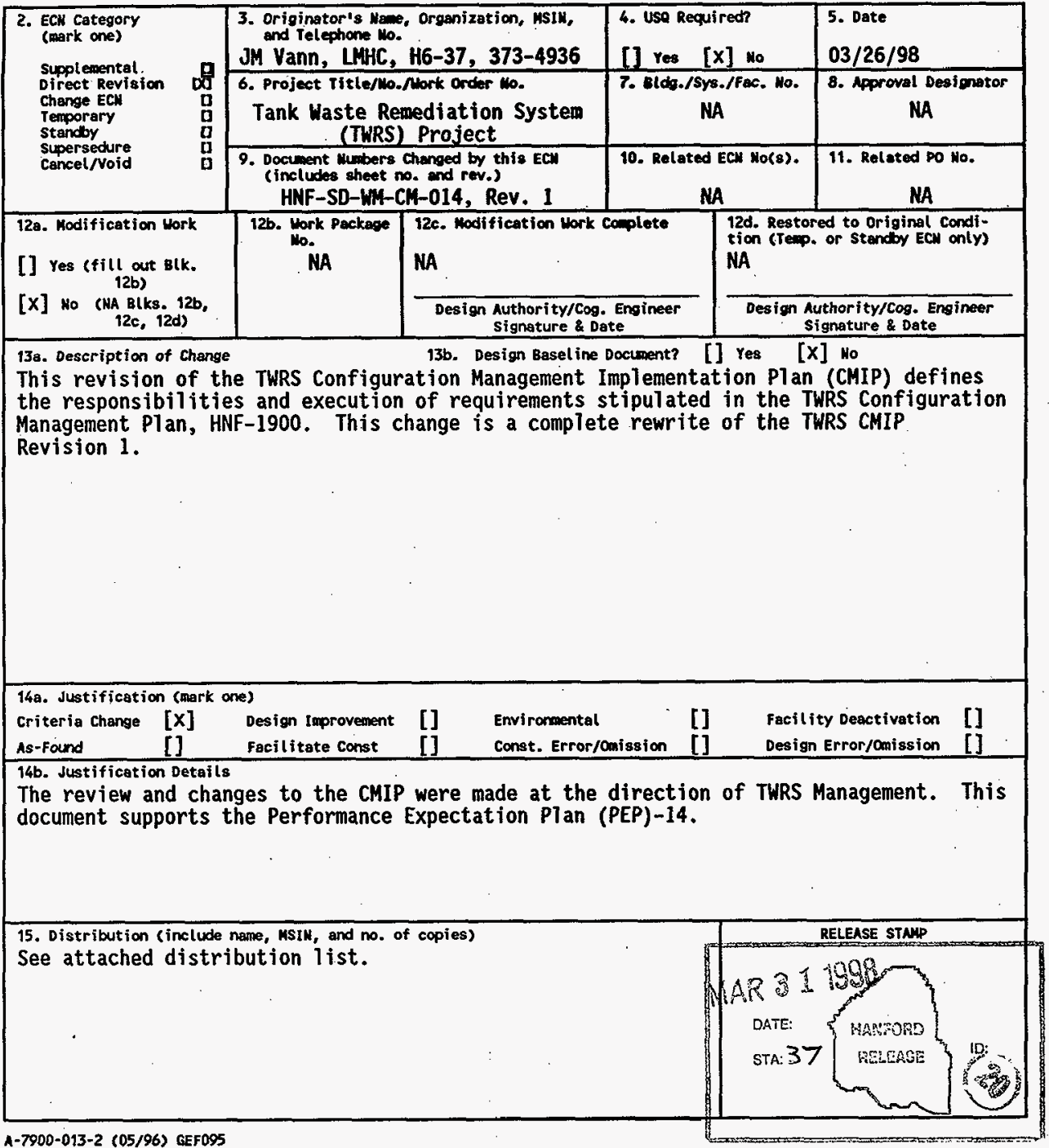




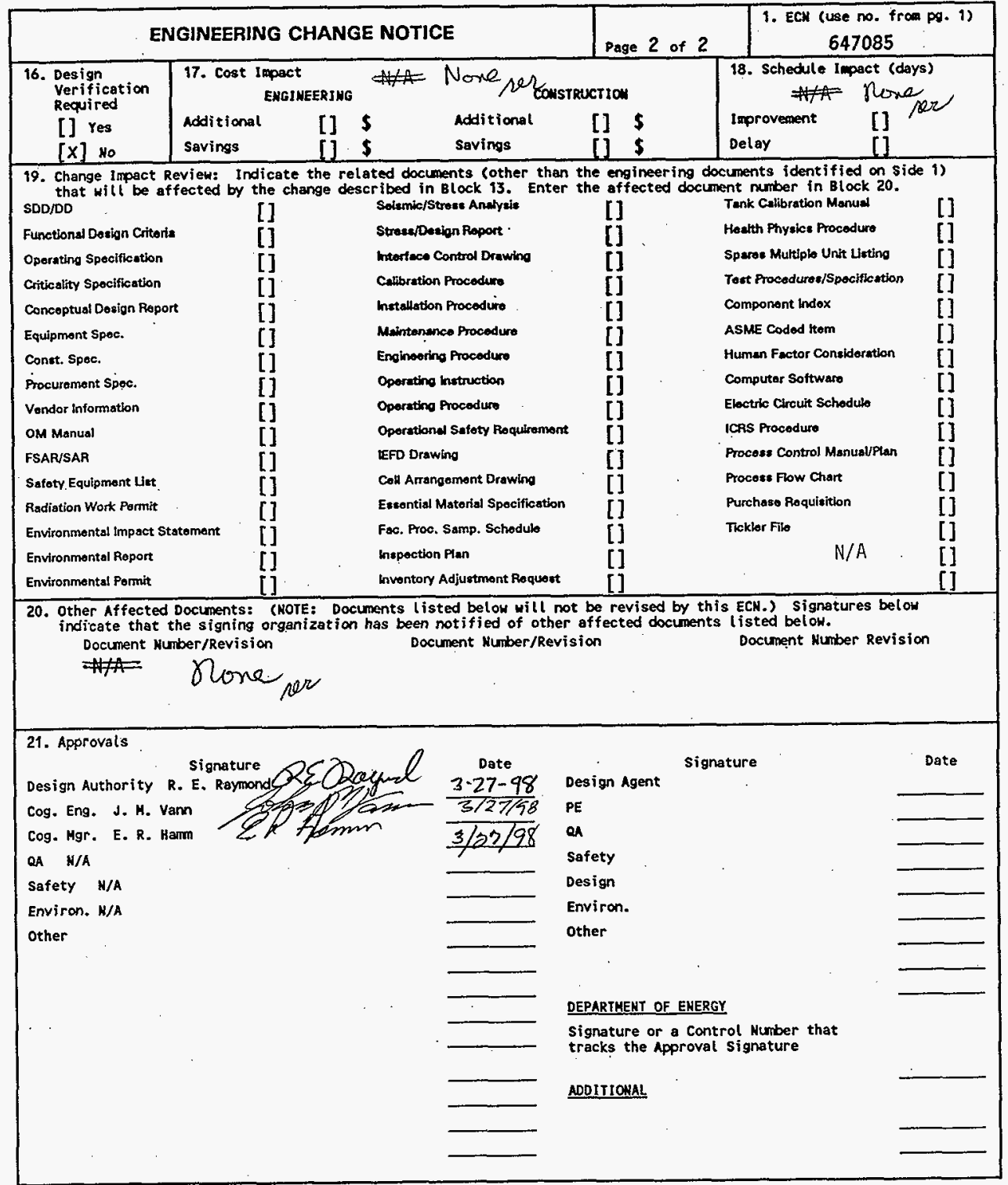




\title{
Tank Waste Remediation System Configuration Management Implementation Plan
}

\author{
J. H. Vann \\ Lockheed Martin Hanford Company, Richland, WA 99352 \\ U.S. Department of Energy Contract DE-ACO6-96RL13200
}

$\begin{array}{ll}\text { EDT/ECN: } 647085 & \text { UC: } 2030 \\ \text { Org Code: } 74 A 00 & \text { Charge Code: DIMAB } \\ \text { B\&R Code: EW3130010 } & \text { Total Pages: } 70\end{array}$

Key Words: TWRS, Configuration Management Implementation Plan

Abstract: The Tank Waste Remediation System (TWRS) Configuration Management Implementation Plan describes the implementation of the configuration management $(\mathrm{CM})$ program the contractor uses to manage and integrate its programmatic and functional operations to perform work.

TRADEMARK DISCLAIMER. Reference herein to any specific comercial product, process, or service by trade name, tradenark, manufacturer, or otherwise, does not necessarily constitute or fmply its endorsement, recommendation, or favoring by the United States Goverment or any agency thereof or its contractors or subcontractors.

Printed in the United States of America. To obtain copies of this document, contact: WHC/BCS Document Control Services, P.0. Box 1970, Mailstop H6-08, Richland WA 99352, Phone (509) 372-2620; Fax (509) 376-4989.
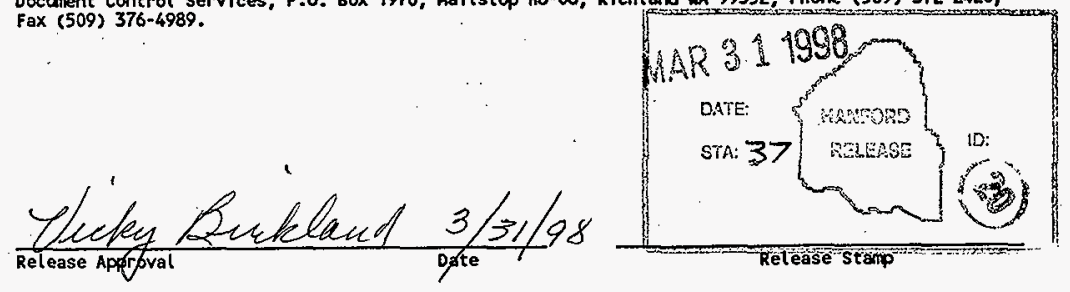

Approved for Public Release 
(2) Title

Tank Waste Remediation System Configuration Management Implementation Plan

CHANGE CONTROL RECORD

(3) Revision (4) Description of Change - Replace, Add, and Delete Pages (7) EDT-603657, 9/26/96

Authorized for Release (0

(7) EDT-603657, 9/26/96

Complete revision, per ECN-614748 $6 / 17 / 97$.

2 RS Complete revision, per ECN-647085. (5) Cog. Engr. (6) Cog. Mgr. Date \begin{tabular}{l|l} 
JM Vann & ER Hamm
\end{tabular} JM Vann $\cdot$ ER Hamm JM Vann 3 Gete ER Hamm

\begin{tabular}{l|l|l} 
& $\mathrm{JM}$ Vann &
\end{tabular}


HNF-SD-WM-CM-014, Rev. 2

UC-510

\title{
Tank Waste Remediation System Configuration Management Implementation Plan
}

\author{
J. M. Vann
}

Lockheed Martin Hanford Corporation

Date Published

March 1998

Prepared by Lockheed Martin Hanford Corporation

Richland, Washington

Prepared for the U.S. Department of Energy

(S) Fluor Daniel Hanford, Inc.

Hanford Management and Integration Contractor for the

U.S. Department of Energy under Contract DE-AC-0696-RA13200 
HNF-SD-WM-CM-014, Rev. 2

This page intentionally left blank. 
Document Title: Tank Waste Remediation System Configuration Management Implementation Plan

Author: J. M. Vann, Lockheed Martin Hanford Corporation

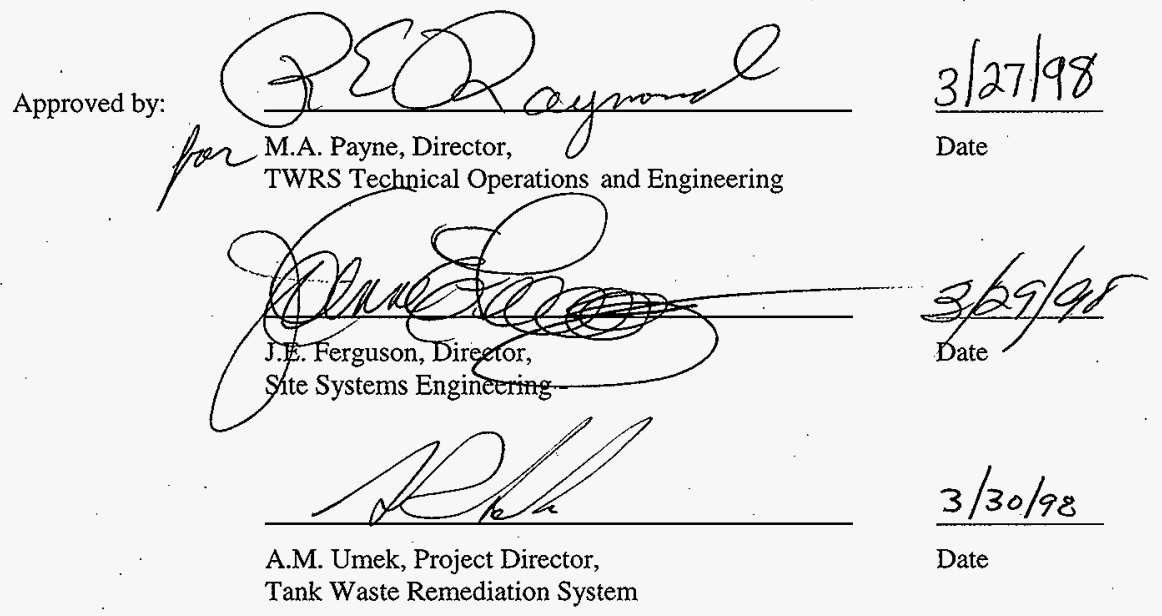


HNF-SD-WM-CM-014, Rev. 2

This page intentionally left blank. 
HNF-SD-WM-CM-014, Rev. 2

\section{EXECUTIVE SUMMARY}

The Tank Waste Remediation System (TWRS) Configuration Management Implementation Plan describes the actions that will be taken by Project Hanford Management Contract Team to implement the TWRS Configuration Management program defined in HNF1900, TWRS Configuration Management Plan. Over the next 25 years, the TWRS Project will transition from a safe storage mission to an aggressive retrieval, storage, and disposal mission in which substantial Engineering, Construction, and Operations activities must be performed. This mission, as defined, will require a consolidated configuration management approach to engineering, design, construction, as-building, and operating in accordance with the technical baselines that emerge from the life cycles. This Configuration Management Implementation

Plan addresses the actions that will be taken to strengthen the TWRS Configuration Management program. 
HNF-SD-WM-CM-014, Rev. 2

This page intentionally left blank. 
HNF-SD-WM-CM-014, Rev. 2

CONTENTS

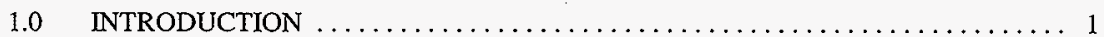

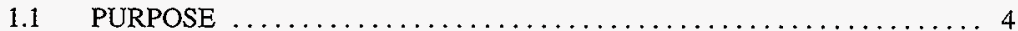

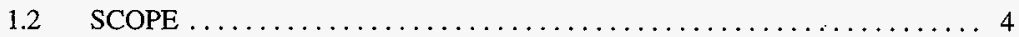

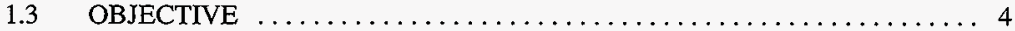

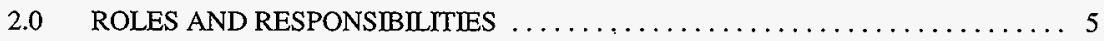

2.1 TWRS TECHNICAL OPERATIONS AND ENGINEERING $\ldots \ldots \ldots \ldots \ldots 5$

2.2 BUSINESS MANAGEMENT $\ldots \ldots \ldots \ldots \ldots \ldots \ldots \ldots \ldots \ldots \ldots \ldots$

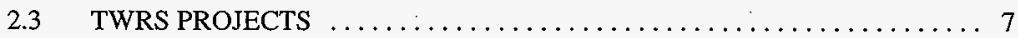

2.4 ENVIRONMENTAL, SAFETY, HEALTH, AND

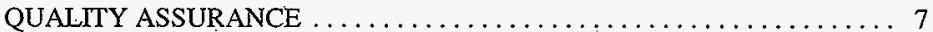

2.5 TANK WASTE OPERATIONS $\ldots \ldots \ldots \ldots \ldots \ldots \ldots \ldots \ldots \ldots \ldots$

2.6 TANK WASTE RETRIEVAL AND DISPOSAL $\ldots \ldots \ldots \ldots \ldots \ldots . .$.

2.7 INFORMATION RESOURCE MANAGEMENT, SYSTEMS

ENGINEERING, AND INTEGRATION $\ldots \ldots \ldots \ldots \ldots \ldots \ldots \ldots$

3.0 TWRS CM PROGRAM IMPLEMENTATION $\ldots \ldots \ldots \ldots \ldots \ldots \ldots \ldots \ldots$

3.1 TWRS CONFIGURATION MANAGEMENT

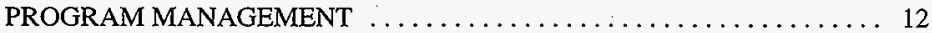

3.2 CHANGE CONTROL ENHANCEMENT $\ldots \ldots \ldots \ldots \ldots \ldots \ldots \ldots \ldots \ldots$

3.3 CONFIGURATION STATUS ACCOUNTING

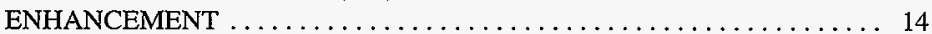

3.4 CONFIGURATION DENTIFICATION IMPROVEMENT $\ldots \ldots \ldots \ldots \ldots 16$

3.5 CONFIGURATION MANAGEMENT ASSESSMENTS $\ldots \ldots \ldots \ldots \ldots 20$

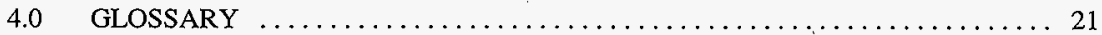

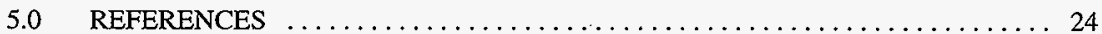


HNF-SD-WM-CM-014, Rev. 2

\section{LIST OF FIGURES}

Figure 1. Tank Waste Remediation System Top-Level Document Relationships . . . . . . . 2

Figure 2. TWRS Configuration Management Document Hierarchy $\ldots \ldots \ldots \ldots \ldots \ldots \ldots$

Figure 3. TWRS Configuration Management Implementation Summary Logic $\ldots \ldots \ldots \ldots 11$

\section{APPENDIX}

A

TWRS CM PROGRAM IMPLEMENTATION LOGIC NETWORK

Page A-1 


\subsection{INTRODUCTION}

Accomplishment of the TWRS mission depends on the ability of TWRS personnel to easily access consistent and valid information related to TWRS items, information, source requirements. Application of the five elements of configuration management (CM) and their underlying principles enable this by providing the mechanisms (processes, information systems, procedures, and training) that are necessary to capture and maintain those information and relationships. The $\mathrm{CM}$ principles are applied through the establishment and implementation of a $\mathrm{CM}$ program. The CM program provides the necessary structure and discipline to define the implementation of the CM principles and establish, maintain, and improve the enabling mechanisms.

The Project Hanford Management Contract (PHMC) CM requirements are prescribed in HNF-MP-013, Configuration Management Plan (FDH 1997a). That document requires TWRS to develop a CM implementation plan or equivalent document that defines a CM system appropriate for TWRS. In accordance with that requirement, the Tank Waste Remediation System (TWRS) CM program was defined and described in HNF-1900, Tank Waste Remediation System Configuration Management Plan,

Ongoing TWRS CM implementation actions and existing mechanisms used to enable that implementation are also described in HNF-1900. Specific mechanisms and requirements are addressed in detail by the Hanford and TWRS procedures referenced by HNF-1900. This TWRS CM Implementation Plan (CMIP) identifies the actions being taken to strengthen implementation of the TWRS CM program. The position that the CMIP plays in the TWRS document hierarchy is shown in Figures 1 and 2. The lower left-hand block in Figure 2 includes lower-tier requirements documents, such as the Tank Farm Standards and Requirements Document (S/RID).

Note: The Tank Farms are subordinate systems of TWRS (a lower level function). The Tank Farm S/RID is not applicable to all of TWRS. The Tank Farm S/RT includes only ES\&H requirements for the Tank Farms. Therefore, documents such as the Tank Farm S/RID are subordinate to TWRS-level plans and requirements. such as this TWRS CMIP.

HNF-SD-WM-CM-016, "TWRS CM Requirement Source Document," is used to correlate and consolidate the various $\mathrm{CM}$ requirements and standards. That document provides a list of TWRS CM requirements that implement the referenced source requirements and standards. HNF-SD-WM-CM-016 will be maintained current with the requirements and standards that are applicable to the TWRS CM program. 


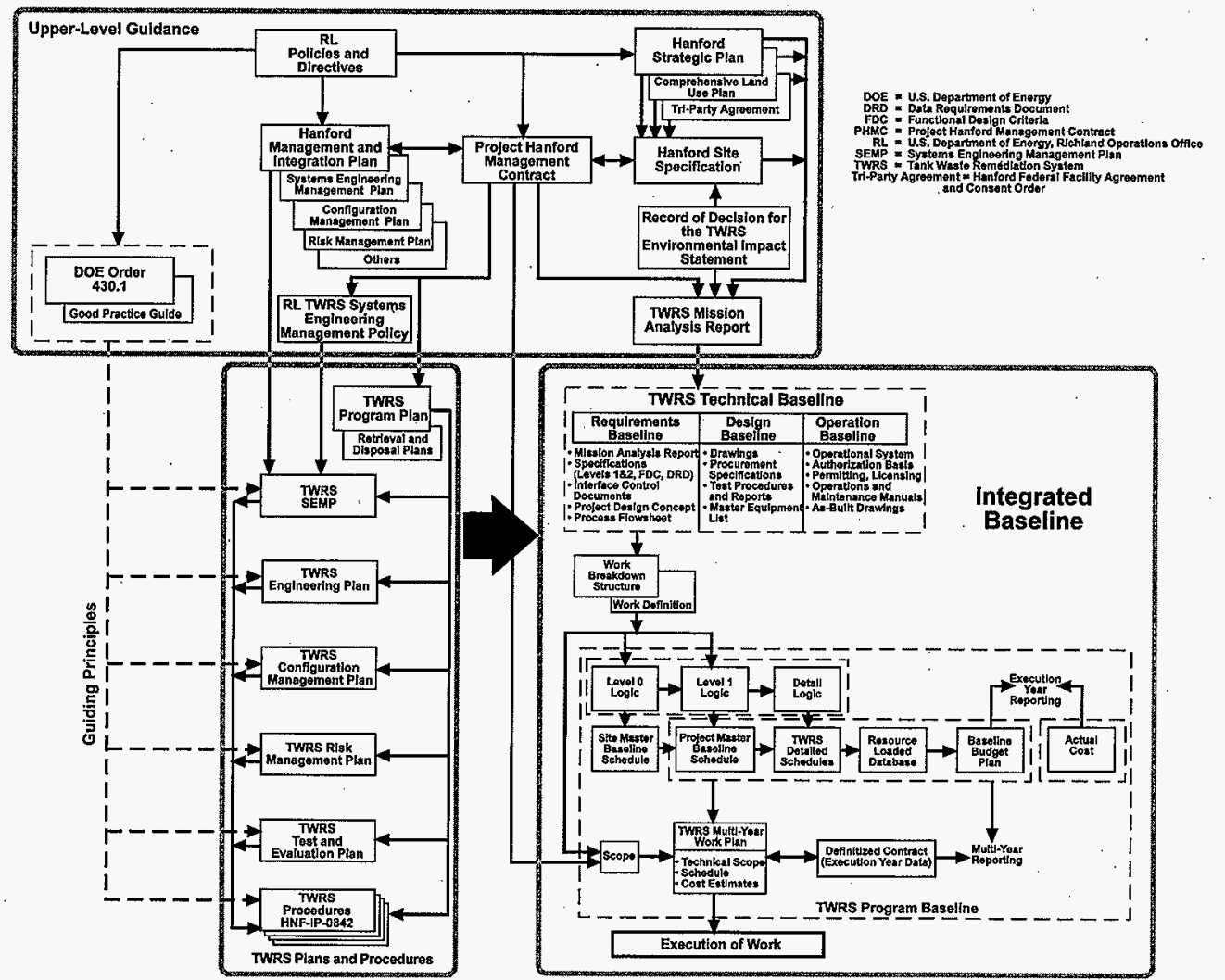


Figure 2. TWRS Configuration Management Document Hierarchy.

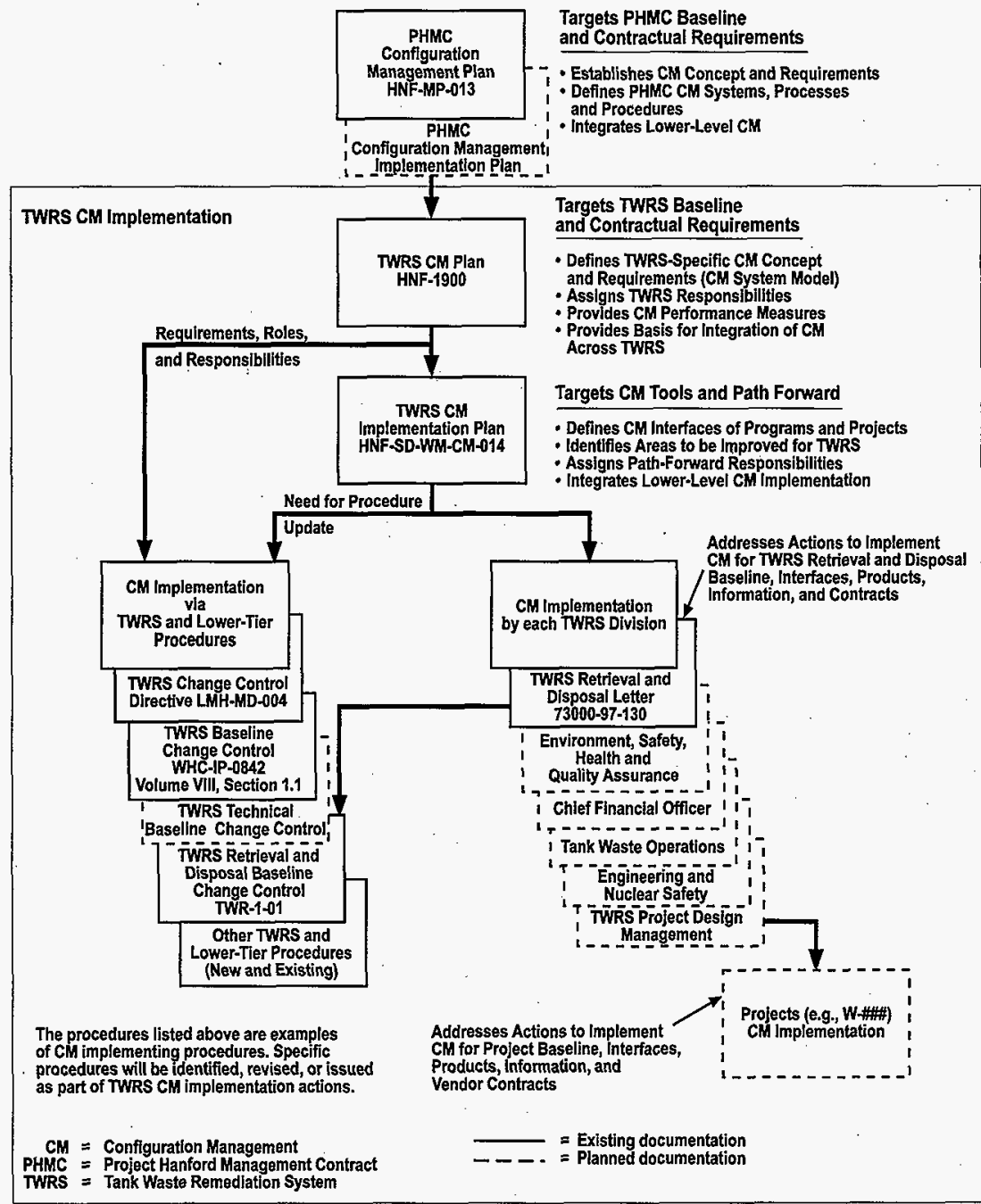




\subsection{PURPOSE}

This CMIP along with the TWRS CM Plan and implementing procedures will satisfy the requirements listed in HNF-MP-013, Section 3.1.2, for PHMC Project CM implementation.

The primary purpose of this CMIP is to identify, plan, and coordinate tasks for strengthening the application of CM across TWRS to a level that is sufficient to maintain and implement the TWRS baseline. This CMIP addresses the actions that are necessary to establish and strengthen the CM mechanisms and to identify, validate, and correct the TWRS baseline (see Section 3.4, Configuration Identification Improvement).

This document will be updated yearly and canceled when TWRS CM implementation can be maintained at a satisfactory level by the ongoing implementation tasks defined in the TWRS $\mathrm{CM}$ Plan and procedures.

\subsection{SCOPE}

The scope of the TWRS CM program is to direct and monitor the development and implementation of configuration management across TWRS. Configuration management principles are applied to establish and maintain the TWRS baseline to implement the contract.

The TWRS CM program establishes the criteria for the scope of the program; defines baselines, concepts, and terminology; identifies and controls configuration management organizational and programmatic interfaces; establishes the policy and criteria for required information systems; and specifies configuration management procedures. Implementation of the configuration management program is based on the TWRS Project mission.

This CMIP applies to improvement of CM implementation by TWRS Programs and projects. Tasks are identified that provide for CM program integration among participants to ensure the integrity and quality of the integrated TWRS baseline, products, and product information and compliance with the integrated site baseline.

\subsection{OBJECTIVE}

The objective of this CMIP is to strengthen TWRS CM implementation using a phased approach. This strengthening of the five CM elements (see Figure 3 ) will be accomplished via recovery tasks and information infrastructure improvement tasks (see Section 3.0). The objective for improvement in each of the CM elements is as follows:

- $\quad$ Objective I - TWRS CM Program Management. Improve ability of TWRS personnel to implement CM. Provide planning, procedures, guidance, and training to integrate CM 
program implementation among participants to ensure the integrity and quality of the integrated TWRS baseline, products, and product information and compliance.

- Objective II - Configuration. Identification. Improve the ability to capture, correlate, control, and access correct configuration information, including the technical, cost, and schedule components of the integrated TWRS baseline (includes basis). Establish adequate identification of configuration items and configuration information. Establish validity and consistency between configuration items and related configuration information.

- Objective III - Controlled TWRS Changes. Improve the ability to generate, control, and implement changes to the integrated TWRS baseline. Improve mechanisms for control of changes to the integrated TWRS baseline so that all changes are developed, evaluated, and dispositioned in respect to the impacts and that traceability to the change basis is established and maintained. Resolve issues with outstanding changes.

- Objective IV - Configuration Status Accounting. Improve the ability to status and correlate configuration items and information. Enhance and integrate processes and information systems used for configuration status accounting.

- Objective V - CM Program Assessments. Improve the use of assessments in evaluating TWRS CM processes and content to enable enhancement and problem resolution implementation.

\subsection{ROLES AND RESPONSIBILITIES}

The following paragraphs define the roles and responsibilities related to improving TWRS CM implementation. Roles and responsibilities for ongoing TWRS CM implementation are defined by HNF-1900 and the referenced procedures. These documents meet the HNF-MP-013 requirement that TWRS define roles and responsibilities for managing CM within the TWRS project.

\subsection{TWRS TECHNICAL OPERATIONS AND ENGINEERING}

The Director, TWRS Technical Operations and Engineering, appoints the TWRS CM Manager and TWRS Technical Operations \& Engineering CM Representative. The Director, TWRS Technical Operations and Engineering, is the TWRS Chief Engineer and sponsors the TWRS Requirements Engineering Technical Change Control Team.

The Director, TWRS Technical Operations and Engineering, provides direction to the TWRS CM Manager regarding application of CM to the TWRS technical baseline. The Director, TWRS Technical Operations \& Engineering, is responsible for identifying TWRS 
Technical Operations \& Engineering configuration items and configuration information, placing them into the TWRS CM program, and maintaining their traceability to and consistency with each other and source requirements.

\subsubsection{TWRS Chief Engineer}

The TWRS Chief Engineer ensures the implementation of the TWRS CM program. The TWRS Chief Engineer is responsible for the configuration management of the TWRS Technical Baseline and its integration with the TWRS Programmatic Baseline.

\subsubsection{TWRS CM Manager}

The TWRS CM Manager manages the TWRS CM program and interfaces with the PHMC CM program. The TWRS CM Manager manages the TWRS CM group and assigns responsibilities within that group for TWRS CM program management tasks. The TWRS CM group defines the TWRS CM Program, coordinating its implementation and providing guidance and technical support to the TWRS Program's CM efforts. The TWRS CM Manager will perform a semiannual review of the CM criteria contained in the TWRS CM procedures.

\subsubsection{Technical Operations \& Engineering CM Representative}

The Technical Operations \& Engineering Representative plans and coordinates implementation of the TWRS CM program on Technical Operations \& Engineering's configuration items and configuration information. The Technical Operations \& Engineering CM Representative works with the TWRS CM group and other TWRS CM Representatives and personnel to resolve TWRS CM program issues.

\subsubsection{TWRS Requirements Engineering Technical Change Control Team}

The TWRS Requirements Engineering Technical Change Control Team is examining the existing technical change control processes and redesigning them into a change control process that provides an improved way of doing change control. The TWRS Requirements Engineering Technical Change Control Team coordinates their efforts with users and personnel responsible for interfacing requirements and processes.

\subsection{BUSINESS MANAGEMENT}

The Director, Business Management, provides direction to the TWRS CM Manager regarding application of $\mathrm{CM}$ to the TWRS programmatic baseline. The Director, Business Management, will ensure the TWRS configuration is maintained sufficient to execute the contract. The Director, Business Management, is responsible for identifying Business Management's configuration items and configuration information, placing them into the TWRS CM program, and maintaining their traceability to and consistency with each other and source 
requirements. The Director, Business Management, appoints the Business Management's CM Representative and TWRS Change Control Administrator.

\subsubsection{TWRS Chief Financial Officer}

The Chief Financial Officer is responsible for the configuration management of the TWRS-level Programmatic Baseline and its integration with the TWRS Technical Baseline.

\subsubsection{Business Management CM Representative}

The Business Management CM Representative plans and coordinates implementation of the TWRS CM program on Business Management's configuration items and configuration information. The Business Management CM Representative works with the TWRS CM group and other TWRS CM Representatives and personnel to resolve TWRS CM program issues.

\subsubsection{TWRS Change Control Administrator}

The TWRS Change Control Administrator implements TWRS CM Program requirements that apply to the control of changes to the integrated TWRS baseline. The TWRS Change Control Administrator manages the TWRS programmatic change control process and administers the TWRS programmatic and technical change control processes at the TWRS level.

\subsection{TWRS PROJECTS}

The Director, TWRS Projects, is responsible for identifying Projects' configuration items and configuration information, placing them into the TWRS CM program, and maintaining their traceability to and consistency with each other and source requirements. The Director, TWRS Projects, appoints the Projects' CM Representative.

\subsubsection{Projects CM Representative}

The Projects CM Representative is responsible for planning and coordinating implementation of the TWRS CM program on Projects' configuration items and configuration information. The Projects CM Representative works with the TWRS CM group and other TWRS CM Representatives and personnel to resolve TWRS CM program issues.

\subsection{ENVIRONMENTAL, SAFETY, HEALTH, AND QUALITY ASSURANCE}

The Director, Environmental, Safety, Health, and Quality Assurance (ESH\&QA), is responsible for identifying ESH\&QA's configuration items and configuration information, placing them into the TWRS CM program, and maintains their traceability to and consistency 
with each other and source requirements. The Director, ESH\&QA, appoints the ESH\&QA CM Representative.

\subsubsection{ESH\&QA CM Representative}

The ESH\&QA CM Representative plans and coordinates implementation of the TWRS $\mathrm{CM}$ program on ESH\&QA's configuration items and configuration information. The ESH\&QA CM Representative works with the TWRS CM group and other TWRS CM Representatives and personnel to resolve TWRS CM program issues.

\subsubsection{Quality Assurance}

Quality Assurance assists the TWRS CM group in performing and evaluating CM assessments: Quality Assurance identifies CM-related issues discovered as part of other Quality Assurance assessments. When the CM issues are at the TWRS level, Quality Assurance ensures that the TWRS CM group participates in identification of the resolution. When the CM issues are below the TWRS level, Quality Assurance notifies the TWRS CM group of the issue and its proposed resolution.

\subsection{TANK WASTE OPERATIONS}

The Director, Tank Waste Operations, is responsible for identifying Tank Waste Operations' configuration items and configuration information, placing them into the TWRS CM program, and maintaining their traceability to and consistency with each other and source requirements. The Director, Tank Waste Operations, appoints the Tank Waste Operations CM Representative.

\subsubsection{Tank Waste Operations CM Representative}

The Tank Waste Operations CM Representative plans and coordinates implementation of the TWRS CM program on Tank Waste Operations' configuration items and configuration information. The Tank Waste Operations CM Representative works with the TWRS CM group and other TWRS CM Representatives and personnel to resolve TWRS CM program issues.

\subsection{TANK WASTE RETRIEVAL AND DISPOSAL}

The Director, Tank Waste Retrieval and Disposal, is responsible for identifying Tank Waste Retrieval and Disposal's configuration items and configuration information, placing them into the TWRS CM program, and maintaining their traceability to and consistency with each other and source requirements. The Director, Tank Waste Retrieval and Disposal, appoints the Tank Waste Retrieval and Disposal CM Representative. 


\subsubsection{Tank Waste Retrieval and Disposal CM Representative}

The Tank Waste Retrieval and Disposal CM Representative plans and coordinates implementation of the TWRS CM program on Tank Waste Retrieval and Disposal's configuration items and configuration information. The Tank Waste Retrieval and Disposal CM Representative works with the TWRS CM group and other TWRS CM Representatives and personnel to resolve TWRS CM program issues.

\subsection{INFORMATION RESOURCE MANAGEMENT, SYSTEMS ENGINEERING, AND INTEGRATION}

The Vice President, Information Resource Management, Systems Engineering, and Integration provides technical support to enable the improvement and implementation of the TWRS CM Program. This includes responsibility for enhancement of the enabling mechanisms (e.g., information systems and related processes and procedures, such as document and records management services). The Vice President, Information Resource Management, Systems Engineering, and Integration is responsible for ensuring the configuration management of these enabling mechanisms satisfies TWRS requirements.

\subsection{TWRS CM PROGRAM IMPLEMENTATION}

Requirements for TWRS Project CM implementation are defined in HNF-MP-013. While HNF-1900 and this CMIP address those requirements at the level that CM program management (e.g., planning and integration) is being performed, the tasks in this CMIP will establish or revise TWRS CM procedures and other procedures. Those procedures will address the specifics of TWRS CM program implementation.

Implementation of the TWRS CM program is covered by a number of documents appropriate to the level and detail of the implementation task. In accordance with HNF-MP-013, HNF-1900 identifies the scope of TWRS CM; defines roles, responsibilities, and mechanisms for managing TWRS CM; and describes the TWRS CM program. HNF-1900 references the Hanford and TWRS procedures and documents that are needed to rneet the HNF-MP-013 requirements to define the TWRS requirements and mechanisms for identifying configuration items and information, controlling changes, statusing the configuration, and assessing the TWRS CM program. As required by HNF-MP-013, CM criteria contained in the $\mathrm{CM}$ procedures will be reviewed on a semiannual basis, or upon significant change to the CM criteria, to ensure the grading decisions that established the criteria are current, consistent, and sufficient to implement applicable requirements.

To implement the requirements of HNF-MP-013 and the TWRS CM program defined in HNF-1900, the TWRS Project needs do the following:

- Maintain the TWRS configuration baseline 
Maintain the CM mechanisms that support and control the baseline Identify and correct deficiencies in the CM mechanisms Identify the items and information that make the TWRS configuration baseline Identify and correct deficiencies in the TWRS configuration baseline.

This CMPP identifies the objectives that need to be met when improving CM implementation, defines the necessary tasks, describes the related logic network, identifies roles and responsibilities, and establishes milestones for improving CM implementation.

TWRS CM implementation is being strengthened by clearly defining roles and responsibilities and enhancing the implementation of configuration identification, configuration status accounting, and change control. Configuration management assessments are being used to evaluate current implementation of $\mathrm{CM}$ and will be used to evaluate the enhanced application of $\mathrm{CM}$.

Actions necessary to strengthen TWRS CM Program implementation are summarized in the following sections of this plan and on Figure 3. Due to the nature and complexity of the systems, processes, and procedures that are used to implement change control, configuration identification, and configuration status accounting; separate plans have been developed to address improvements and enhancements in each of these areas. Implementation milestones are identified on Figure 3 and summarized below. Milestone descriptions and dates are included in the respective subsection of this plan.

\section{Implementation Milestones}

- April 30, 1998 - Each TWRS Program's configuration item list submitted to TWRS CM Group.

- May 30, 1998 - TWRS consolidated configuration item/information list complete.

- April 30, 1999 - Each TWRS Program's configuration identification package submitted to Document Information Management Center (DIMC).

The following paragraphs and Figure 3 summarize the planned actions to implement the TWRS CM Program. Implementation relies on the coordinating $\mathrm{CM}$ organization to define and manage the TWRS CM Program and each TWRS Program to ensure their procedures, processes, and systems implement the TWRS CM Program. The TWRS Programs will identify and establish control over current configuration items and information. The CM implementation actions for which each TWRS Program are responsible are described in Appendix A. 


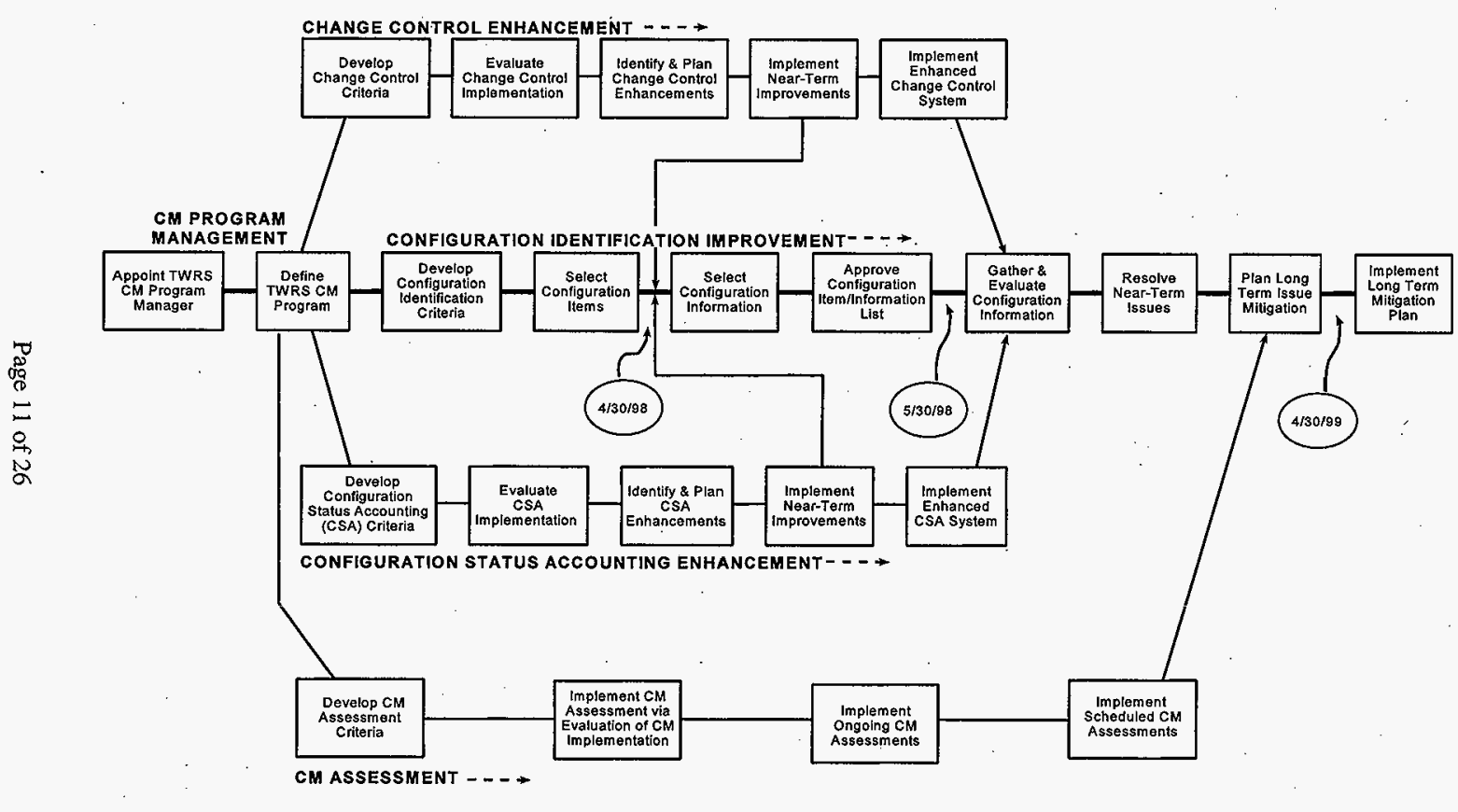




\subsection{TWRS CM PROGRAM MANAGEMENT}

This set of tasks is necessary to meet Objective I of this CMIP. The TWRS CM program will be managed to coordinate $\mathrm{CM}$ implementation planning and implementation tasks. Planning for CM implementation will be included in and be consistent with TWRS and the TWRS Programs' fiscal year planning.

\subsubsection{Appoint TWRS CM Manager}

This task has been completed. It required the assignment of related responsibilities to an organization that would manage program development and maintenance and coordinate implementation. These responsibilities were assigned to TWRS CM within TWRS Technical Operations and Engineering.

\subsubsection{Define TWRS CM Program}

This task has been completed. As required by HNF-MP-013, the TWRS CM program is defined and described in HNF-1900. The TWRS. CM Plan also contains general organization responsibilities for the implementation and identifies the mechanisms used for ongoing $\mathrm{CM}$ implementation. The TWRS CM Plan will be updated, as necessary to comply with requirements, reflect enhancement made in accordance with this CMIP, and incorporate process improvements.

The TWRS CM Plan also describes the status of CM implementation at the time it was issued and establishes the role that this CMIP plays in enhancing CM mechanisms and CM implementation.

\subsection{CHANGE CONTROL ENHANCEMENT}

Change control enhancement is required to satisfy Objective III of this CMIP and to resolve problems with the existing change backlog and provide for the necessary control and useability of changes from the point of initiation of a change request through development, dispositioning, implementation, and closure. The enhancements will improve the responsiveness and effectiveness of controls for technical changes and integration of technical and programmatic changes.

These actions are necessary to satisfy the change control requirements defined in HNF-1900 and implement the change control process defined by HNF-1900. Change control enhancement tasks delineated by this CMIP will further define the TWRS-specific requirements and mechanisms for controlling changes as is required by HNF-MP-013.

The TWRS programmatic change control process has been updated by the TWRS change control administrator. The process is being maintained consistent with the PHMC programmatic change control process and the TWRS technical change control process. 
Technical change control enhancements are being addressed by the TWRS Requirements Engineering Technical Change Control task team and will be described in more detail in TWR-2411, Tank Waste Remediation System Technical Change Control Implementation Plan, Bryan, 1998, that will be issued in the near future this year. That plan will include task descriptions, responsibilities, and dates. Change control enhancement tasks are being performed in coordination with TWRS CM improvement efforts and PHMC efforts (e.g., TWRS configuration status accounting enhancement, HANDI 2000 effort).

The existing technical change control mechanisms have been examined to identify needs, requirements, and problems. Based on the results of that examination, a new technical change control process has been developed. Implementation of the new technical change control processes via enabling systems, procedures, and training is being planned. This includes developing better change control system criteria and performing near-term and long-term mitigation actions to provide an enhanced change control system. Actions are also being taken to identify and resolve issues with existing configuration changes.

\subsubsection{Develop Change Control Criteria}

The change control criteria are included in the TWRS CM Plan and its referenced procedures. The TWRS Requirements Engineering Technical Change Control Team has refined the change control criteria. The new criteria are based on the requirements defined in the TWRS CM Plan, interfacing systems and processes, and an evaluation of user needs. The refined criteria will be included in TWR-2411 and implemented in accordance with that document.

\subsubsection{Evaluate Change Control Implementation}

This task has been completed. Evaluation results will be contained in TWR-2411. The results of the evaluation provided bases for the developing change control enhancements and planning their implementation.

\subsubsection{Identify and Plan Change Control Enhancements}

This task is being performed by the TWRS Requirements Engineering Technical Change Control Team. The team has identified the primary areas of technical change control that need to be enhanced and developed recommendations regarding those enhancements. These recommendations and subsequent task planning will be included in TWR-2411. The enhancements include improvements that can be made within a short- or near-term period as well as improvements that will be accomplished over a longer period.

\subsubsection{Implement Near-term Improvements}

Near-term improvements to the change control process will be implemented in accordance with the technical change control implementation plan. To enable the necessary improvement of the TWRS configuration baseline, it is important that these include improvements that are needed to enable change control of the configuration item and 
configuration information lists as they are produced (see Section 3.4, Configuration Identification Improvement). Near term improvements are those improvements that are necessary to maintain safety, required to accomplish near term mission objectives (e.g., enable a task on the TWRS Program Logic), or easy to make within the prescribed time period.

\subsubsection{Implement Enhanced Change Control System}

The TWRS Requirements Engineering Technical Change Control Team has developed the change control process that will replace the existing TWRS change control process. Some of the features of the enhanced change control process will be part of near-term improvements. Full implementation of the new change control process is being included in long-term planning. The new change control process and related implementation actions will be included in TWR-2411.

These enhancements are necessary to satisfy Objective $I$ of this CMIP and to enable the required maintenance and improvement of the TWRS configuration baseline (see Section 3.4, Configuration Identification Improvement). Completion of these enhancements is necessary to implement the technical change control process defined in HNF-1900 and to satisfy the change control requirements listed in HNF-MP-013.

\subsection{CONFIGURATION STATUS ACCOUNTING ENHANCEMENT}

Configuration status accounting enhancement is necessary to satisfy Objective IV of this CMIP and provide the required level of maintenance and improvement for the TWRS configuration baseline (see Section 3.4, Configuration Identification Improvement). Completion of these enhancements implements the configuration status accounting system defined in HNF-1900 and to satisfy the configuration status accounting requirements listed in HNF-MP-013.

Configuration status accounting enhancement is required to provide the necessary control and retrievability of configuration information. The configuration status accounting system is being enhanced to improve the control and retrievability of configuration information. This enhancement is being addressed as part of two TWRS improvement efforts (TWRS CM Information System and TWRS Requirement Engineering Technical Change Control). These efforts are being performed in coordination with the HANDI 2000 effort and Document and Records Management's efforts to improve the Hanford Document Control System (HDCS) and Records Management and Information System (RMIS).

The TWRS CM Information System project is enhancing configuration status accounting by evaluating the existing systems, identifying problems and areas for improvement, and implementing system changes. This includes improvement to the correlation and statusing of configuration information contained within the configuration status accounting system. These actions are being addressed by the TWRS CM Information System effort. This effort is documented in HNF-SD-TWR-CSWD-001, TWRS Configuration Management Information 
System Project Document, Gneiting, 1997. That document will be revised to reflect the progress of related planning and enhancement activities.

The TWRS Requirement Engineering Technical Change Control Team has identified and is refining user needs and configuration status accounting process criteria. These will be reflected in TWR-2411.

\subsubsection{Develop Configuration Status Accounting Criteria}

Configuration status accounting criteria have been developed and are included in the TWRS CM Plan and its referenced procedures. The criteria are being refined as noted in Section 3.3 above. The refined criteria are necessary to select the appropriate set of TWRS information to capture and control to enable accomplishment of the TWRS mission.

Criteria improvement is concentrating on the set of criteria used to manage configuration documentation and images and enable electronic work flow. Electronic work flow will allow the documents and changes to them to be prepared, reviewed, approved, issued, and distributed via the Hanford Local Area Network (HLAN) and the Internet. Changes to the criteria are based on requirements defined in the TWRS CM Plan, interfacing systems and processes, and an evaluation of user needs.

\subsubsection{Evaluate Configuration Status Accounting Implementation}

This task has been completed. Evaluation results are in HNF-SD-TWR-CSWD-001 and TWR-2411. The results of the evaluation provided bases for developing configuration status accounting enhancements and planning their implementation.

\subsubsection{Identifying and Plan Configuration Status Accounting Enhancements}

HNF-SD-TWR-CSWD-001 and TWR-2411 identify the necessary configuration status accounting enhancements. HNF-SD-TWR-CSWD-001 identifies the scope of configuration status accounting enhancement activities, assigns roles and responsibilities, and defines implementing tasks and the schedule for those tasks. The enhancements will be planned and implemented via HNF-SD-TWR-CSWD-001, which will be revised to align with progressing efforts.

\subsubsection{Implement Near-term Configuration Status Accounting Improvements}

HNF-SD-TWR-CSWD-001 identifies enhancements being made in the near future. These enhancements are necessary to enable TWRS to identify configuration items and configuration information and communicate that information. This relationship to configuration identification improvement is reflected in Figure 2. Enhancements that take longer to mitigate will be resolved by implementing an enhanced configuration status accounting system. 


\subsubsection{Implement Enhanced Configuration Status Accounting System}

Implementation of an enhanced configuration status accounting system is necessary for TWRS to establish and maintain a valid configuration identification baseline. Figure 3 reflects the relationship between configuration status accounting enhancement and configuration identification improvement. As stated previously, implementation of an enhanced configuration status accounting system is reflected in HNF-SD-TWR-CSWD-001.

Completion of these enhancements is necessary to satisfy Objective IV of this CMIP and to enable the required maintenance and improvement of the TWRS configuration baseline (see Section 3.4, Configuration Identification Improvement). Completion of these enhancements will implement the configuration status accounting system defined in HNF-1900 and satisfy the related requirements listed in HNF-MP-013.

\subsection{CONFIGURATION IDENTIFICATION IMPROVEMENT}

The existing identification of the TWRS configuration needs to be strengthened to determine the current status and to provide the remaining information that is necessary to enable the TWRS mission. The mechanisms that control and maintain the TWRS configuration need to be improved to such that the reestablished configuration baseline is maintained. Configuration identification improvement is a recovery effort that is necessary to establish and maintain the TWRS configuration baseline sufficient to accomplish the TWRS mission. This set of tasks improves the configuration selection criteria, identifies the set of items and information that need to be controlled to enable the TWRS mission, evaluates, reconciles discrepancies, acquires missing information, and places them under control of the TWRS CM Program.

Improvement of configuration identification is necessary to satisfy Objective $\Pi$ of this CMIP. Completions of these improvements implements the configuration identification mechanisms defined in HNF-1900 and satisfies the configuration identification requirements listed in HNF-MP-013.

As shown in Figure 3 and Appendix A, the ability to implement or improve configuration identification depends on the maturity of change control and configuration status accounting.

\subsubsection{Develop Configuration Identification Criteria}

The configuration identification criteria have been developed but will be updated as part of configuration identification improvement tasks. The criteria are contained in the TWRS CM Plan and its referenced procedures. The TWRS CM plan and implementing procedures will be revised to reflect any changes in the criteria. Specific criteria to be evaluated and improved include configuration item selection criteria, configuration information selection criteria, criteria that define the information necessary to status configuration items and configuration information, criteria for evaluating and correcting configuration information, and criteria for reconstituting configuration information. 


\subsubsection{Select Configuration Items}

This set of tasks is necessary to ensure TWRS is controlling the set of items that are required to enable the TWRS mission. Accomplishment of these tasks implements the configuration item criteria defined by HNF-MP-013 and configuration item selection requirements defined in $\mathrm{HNF}-1900$.

As part of the configuration item selection process, the TWRS Programs will review and provide feedback on the configuration item selection criteria. Once the selection criteria are finalized, each TWRS Program will use it to identify the configuration items for which that program is responsible. Each TWRS Program's configuration item list will be submitted to the TWRS CM group by April 30, 1998. The TWRS CM group will consolidate the resultant list of configuration items.

Where it is not possible to identify configuration items down to the level that work is being performed, items will be identified at the lowest level possible. The need for further configuration item identification will be listed as an issue. The necessary level of configuration identification will be performed as part of near-term or long-term issue resolution.

\subsubsection{Select Configuration Information}

This set of tasks is necessary to ensure TWRS has captured and is controlling information that is required to enable the TWRS mission. Accomplishment of these tasks implements HNF-MP-013 requirements for configuration item identification and identification of documents and implement the HNF-1900 configuration identification process and requirements.

Using the consolidated list of configuration items, TWRS Programs will review and provide feedback on the configuration information selection criteria. The TWRS CM group will make any necessary changes in the criteria. The TWRS Programs will then identify and evaluate the information that they are responsible for. The TWRS Programs will develop a list that identifies the configuration information for which they are responsible. That list will provide the necessary traceability between configuration items and configuration information.

\subsubsection{Approved Configuration Item/Information List}

The TWRS CM group will consolidate the configuration item/information list. The consolidated list will be submitted to TWRS senior management for approval. This will provide a matrix of TWRS configuration items and configuration information and responsible organizations and individuals (owners). The approved list will be used to update the content of the configuration status accounting system and remove items and information, for which control is not desired, from the CM system. This will establish the TWRS configuration information baseline that will be evaluated and corrected in subsequent activities. The configuration item/information list will be completed by May 30, 1998. 
The configuration item/information list will provide a basis for updating the TWRS CM implementation planning. This may result in changes to specific tasks or the schedule (e.g., the date, April 30, 1999, for completion of near-term issues may be changed). Where there is a need for further configuration information identification, it will be listed as an issue. This configuration information issue will be addressed as part of near-term or long-term issue resolution.

\subsubsection{Gather and Evaluate Configuration Information}

Each TWRS Program will gather and evaluate the configuration information for which the program is responsible. This evaluation is to ensure the configuration information is sufficient to support accomplishment of the TWRS mission. This is also necessary to satisfy configuration identification requirements defined by HNF-MP-013 and HNF-1900.

Configuration information will be gathered from all readily available sources. Due to the amount of information that will be retrieved or acquired from vendors, the TWRS Programs will request the information from the records system and vendors via the DIMC. The DIMC will act as a single point of contact to coordinate the retrieval and acquisition of information.

This configuration information will be evaluated as to whether it is sufficient to support the program's configuration items and mission. The intent is to ensure that the program has sufficient information to accomplish assigned tasks. During this evaluation any issues (insufficiencies) with configuration information will be identified. These issues will fall into two categories (i.e., near-term and long-term) related to whether they can be resolved in the near-term or are long-term issues that will take a longer period of time to resolve. Each TWRS Program will develop a long-term mitigation plan for those issues that need a longer period of time to resolve.

To complete this task each TWRS Program will submit a configuration identification package to the TWRS CM group. This package will identify the status of the configuration information that encompasses the Program's scope of responsibility, any corrections resulting from near-term issue resolution, and any long-term mitigation plan.

\subsubsection{Resolve Near-Term Issues}

Completion of near-term configuration identification issues will target those issues that need to be resolved to perform activities listed on the TWRS Program Logic and lower-level logics. Emphasis will be placed on enabling the TWRS Program Logic critical path activities that are identified by the program logic to proceed. The following are examples of near term issues:

A need to as-built a tank to support a deliverable or task identified on the program logic that is due within the year.

- The need to determine the design basis of an existing waste transfer system (pump operating pressure \& flow limits, valve pressure limits \& flow characteristics, 
etc.), in order to determine whether the system has the necessary capabilities for use within the next few months.

- An operating procedure that does not exist and is needed to perform a transfer that is scheduled within the year.

The task of resolving near-term issues will overlap the gathering and evaluation of configuration information. When possible, issues with the configuration information will be resolved and planned as soon as possible once the issue is identified. Correction to configuration information may be provided to the TWRS CM group as the issues are corrected or as part of the configuration identification package. Issues that are still open at the end of the two efforts will be included in that TWRS Program's long-term mitigation plan:

Near-term CM implementation improvement will be completed on resolution of nearterm issues and the update of configuration status accounting in accordance with the configuration identification package.

Completion of near-term CM implementation improvements will occur by April 30, 1999. At this point, ongoing implementation of CM will occur as part of each CM program's normal work activities and will be planned accordingly. Open issues will have been identified within the TWRS Programs' mitigation plans and will be tracked to completion of the associated resolutions.

Upon completion of near-term activities, the majority of the TWRS CM Program will be implemented and most HNF-MP-013 requirements for TWRS CM implementation will be satisfied. The remaining issues will have been identified and included in the TWRS Programs'. CM implementation plans.

\subsubsection{Plan Long-term Issue Mitigation}

When a TWRS Program has open CM issues that cannot be completed as part of nearterm CM implementation, mitigation of those open issues will be planned and included in the Program's CM implementation plans. The plan will identify the issue(s) to be resolved, related actions to be taken, the schedule for those actions, and relevant roles and responsibilities.

Actions listed in the program's CM implementation plan will be included in fiscal year planning. The following are examples of long-term issues:

- A need to correct information for a two day training course that is related to a task that will occur two years from now.

- The need to determine the design basis of an existing waste transfer system (pump operating pressure \& flow limits, valve pressure limits \& flow characteristics, etc.) In order to determine whether the system has the necessary capabilities to perform a task in the TWRS Program Logic. 
- An operating procedure that does not exist and is needed to perform a transfer that is scheduled over a year away.

\subsubsection{Implement Long-term Mitigation}

Actions to resolve open configuration information issues will be taken in accordance with program's CM implementation plan. Each TWRS Program will track their mitigation actions to closure. Upon completion and closure of the last mitigating action, long-term improvement of $\mathrm{CM}$ implementation is complete. Ongoing implementation of $\mathrm{CM}$ will occur as part of normal work activities and will be planned accordingly. Mitigation needs to be completed before turnover of configuration items or configuration information to non-TWRS entities.

\subsection{CONFIGURATION MANAGEMENT ASSESSMENTS}

Assessments are necessary to evaluate and improve the effectiveness of the CM program, functional and physical capability of products, and testing. CM assessments are being performed in a variety of manners as appropriate to evaluate existing processes and test enhancements and new processes. Since CM assessments are performed as part of the tasks to enhance and improve CM implementation, details for this activity are not reflected in Figure 3 or the Appendix. CM assessments will be used to evaluate the success of CM implementation. Criteria and procedures for performing $\mathrm{CM}$ assessments will be factored into the Quality Assurance assessment program.

This set of tasks satisfies Objective $\mathrm{V}$ of this CMIP and implements the CM assessment requirements of HNF-MP-013 and HNF-1900.

\subsubsection{Develop CM Assessment Criteria}

The TWRS CM assessment criteria have been developed. The criteria are included in HNF-1900 and its referenced procedures. The TWRS Requirements Engineering Technical Change Control Team has refined the change control criteria. The new criteria are based on the requirements defined in HNF-1900, interfacing systems and processes, and an evaluation of user needs.

\subsubsection{Implement CM Assessment Via Evaluation of CM Implementation}

As stated earlier, the teams involved in change control enhancement, configuration status accounting enhancement, and configuration identification improvement have further refined the CM assessment criteria to meet the needs specific to their efforts. This provides an in-depth assessment of both the functioning of the configuration management program and its implementation. 


\subsubsection{Implement Ongoing CM Assessments}

As the configuration information baseline is established, a process for performing ongoing configuration management assessments will be developed. The process will be proceduralized and assessment actions will be included in fiscal year planning.

\subsubsection{Implement Scheduled CM Assessments}

Implementation of scheduled configuration management assessments depends on the existence of a well-defined configuration information baseline and $\mathrm{CM}$ system that can be assessed. This relationship is reflected in Figure 3. Once the configuration information baseline has been established it will be assessed to identify configuration identification issues and other $\mathrm{CM}$ implementation issues. Provision for resolution of those issues will be included as part of the $\mathrm{CM}$ assessment program and $\mathrm{CM}$ program management tasks.

\subsection{GLOSSARY}

As-Built - Documentation (for example, Piping and Instrument Diagrams, and database records) verified by physical inspection as depicting the actual physical configuration and verified as consistent with the design requirements. .

Assessments - A CM program element that encompasses the following functions: conducting programmatic and physical configuration assessments, performing periodic equipment performance monitoring, and performing post-modification testing.

Baseline - A set of documented decisions that constitutes an established reference position for control, status accounting, reviews, assessments, and changes. These decisions are delineated in selected technical and programmatic documents that are identified and controlled. Baselines are continually changing via an orderly control of changes as required in DOE-HQ, RL, and the configuration management programs, especially during the development phase. Therefore, the current baseline is always the previously approved baseline with all approved changes.

Basis - The basis is the full set of information used to establish a function, requirement, or baseline. The basis explains why a function, requirement, or baseline has been specified in a particular manner or as a particular value. The basis consists of the inputs, constraints (e.g., regulations), analysis, studies, and calculations. The basis includes that subset that relates to safety and the authorization basis.

Change - Any alteration or addition, temporary or permanent, to a product. Changes not within current design requirements involve design changes. For system, structure, or components, identical replacements are not changes. 
Change Control - A process that ensures all changes are properly identified, reviewed, approved, implemented, tested, and documented.

Change Control Administrator - The person responsible for processing proposed changes and maintaining the database that tracks change requests and change request status.

Change Request - The document used to initiate changes to approved configuration information (e.g., program cost, schedule, and technical baselines) and uniquely identified by a change identification number. The change request is used to document change proposals that require dispositions by the appropriate Change Control Board member.

Configuration - The functional and/or physical characteristics as delineated in configuration information and achieved in a configuration item (form, fit, and function).

Configuration Baseline - The set of configuration items and configuration information at a defined point in time. This includes relationships between the configuration items, configuration information, and source requirements and the status of the configuration items and information.

Configuration Identification Package - A compilation of information that identifies a Program's configuration items and configuration information, correlates the two, identifies their respective status and any open issues, and provides other necessary CM data. The package may also include changes to existing information and new information to be issued. The package is a deliverable at the end of near-term configuration identification improvement tasks listed in this CMIP. It is used to update and correct configuration status accounting.

Configuration Item - A product that has been selected to be controlled and for which the configuration and configuration information (including basis) will be managed. (Example: A doorknob may be a product but is not controlled and consequently is not considered a configuration item. A disposal tank is a more important product and is controlled as a configuration item.)

Configuration Information Selection Criteria - The requirements and guidance used to determine whether a set of information is important enough to control as configuration information.

Configuration Information - Data and documentation that define, provides basis for, or otherwise have an important relationship to a product and is controlled to maintain that relationship.

Configuration Item Selection Criteria - The requirements and guidance used to determine whether an item is important enough (e.g., due to cost, safety, or mission considerations) to control as a configuration item.

Configuration Management - An integrated management program used to established consistency among requirements, basis, functional configuration, and documentation, and maintained this consistency throughout the life of the product as changes occur. 
Configuration Management Process Criteria - The set of requirements that apply to the processes that are used to implement the TWRS CM program.

Configuration Management Selection Criteria - A general term used to encompass the configuration item selection criteria, and configuration information selection criteria.

Configuration Status Accounting - The CM activity that addresses the capture, storage of, and access to configuration information needed to manage products and product information effectively.

Documents - Any electronic, text-type, or pictorial information.

Document Control - A process that stores and controls, tracks status (especially during revisions), and retrieves documents.

Enabling mechanism - An interrelated set of processes, systems, procedures, and training that provide the ability for a task to be performed.

Information Infrastructure Improvement Task - A task that is necessary to improve or enhance CM processes, systems, procedures, and training to the desired level to enable other work activities.

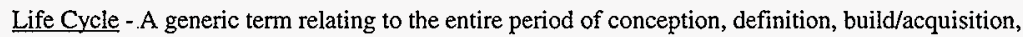
distribution, operation, decommissioning, and disposal of a product.

Mitigation Plans - Short and Long-Term plans that will be developed to resolve issues in identification and location of configuration information that is not readily available for entry into the Configuration Status Accounting system.

Ongoing Implementation Task - A task that applies one or more of the five CM functions to normal ongoing activities (e.g., documentation of design activities, document control, records management, product validation and test, procedure control, work packages, change implementation, as-built verification and validation, and closure).

Participant - An organization that is performing tasks in direct support of the TWRS mission. An organization to which the TWRS configuration management program applies or that provides support to the TWRS configuration management program.

Physical Configuration - The actual physical makeup, location, arrangement, and material condition of a product.

Product - Any item produced and/or used by TWRS including physical items (e.g., tank waste, procured goods), software, documents; data, or systems, structures, or components (equipment). A configuration item is a subset of products that has been chosen to be controlled.

Programmatic Baseline -The defined and approved configuration of the program management element (e.g., Technical Scope, Cost, Schedule, Performance Agreements and Measures) of the TWRS Project, a TWRS Program, etc., down to the task level. 
Programmatic Changes - Changes to organized sets of activities in direct support of a specific mission area. Programs are typically made up of activities (e.g., Cost, Schedule, Performance Agreements and Measures) that manage the technical basis.

Recovery Task - A task to reestablish the validity of the content and relationship of source requirements, configuration information, and configuration items (see Figure 2 of the TWRS CM Plan).

Technical Baseline - The defined and approved physical/functional configuration (requirements and design description) of an SSC or computer software. This includes the scope of work that is developed based on the technical requirements.

Technical Changes - Changes to the technical baseline and technical documents that will vary from the original design basis.

\subsection{REFERENCES}

Acree, C. D., Jr., 1998, Tank Waste Remediation System Mission Analysis Report, HNF-SD-WM-MAR-008, prepared by Lockheed Martin Hanford Corporation for Fluor Daniel Hanford, Inc., Richland, Washington.

Borneman, L.E., 1998, Tank Waste Remediation System Environmental Program Plan,HNF-1773, prepared by Lockheed Martin Hanford Corporation for Fluor Daniel Hanford, Inc., Richland, Washington.

Bryan, W. E., 1998, Tank Waste Remediation System Technical Change Control Implementation Plan, TWR-2411, Draft, prepared by Lockheed Martin Hanford Corporation for Fluor Daniel Hanford, Inc., Richland, Washington.

Calmus, R.B., 1997, Tank Waste Remediation System Retrieval and Disposal Mission Immobilized High-Level Waste Storage Plan, HNF-1751, prepared by Lockheed Martin Hanford Corporation for Fluor Daniel Hanford, Inc., Richland, Washington.

Crisp, R.D., Hamm, E.G., Vann, J. M., 1997, Tank Waste Remediation System Configuration Management Plan, HNF-1900, Rev. 0, prepared by Lockheed Martin Hanford Corporation for Fluor Daniel Hanford, Inc., Richland, Washington.

DOE, 1996, Hanford Strategic Plan, DOE/RL-96-82, U.S. Department of Energy, Richland, Washington.

FDH, 1997a, Configuration Management Plan, HNF-MP-013, Rev. 0, Fluor Daniel Hanford, Inc., Richland, Washington.

FDH, 1997, Tank Waste Remediation System Retrieval and Disposal Mission Waste Feed 
Delivery Plan, HNF-1881, Rev. 0, Fluor Daniel Hanford, Inc., Richland, Washington.

Freeman, D. V., 1998, Tank Waste Remediation System Program Plan, HNF-1883, Rev. 0, prepared by Lockheed Martin Hanfórd Corporation for Fluor Daniel Hanford, Inc., Richland, Washington.

Gneiting, B. C., 1997. TWRS Configuration Management Information System Project Document, HNF-SD-TWR-CSWD-001, prepared by Lockheed Martin Hanford Corporation for Fluor Daniel Hanford, Inc., Richland, Washington

Lewis, M.R., O'Neil, M.J., and Swita, W.R., 1998, Tank Waste Remediation System Retrieval and Disposal Mission Initial Updated Baseline Summary Description, HNF-1946, Rev. 1, prepared by Lockheed Martin Hanford Corporation for Fluor Daniel Hanford, Inc., Richland, Washington.

Peck, L. G., 1998, Tank Waste Remediation System Systems Engineering Management Plan, HNF-SD-WM-SEMP-002, Rev. 1, prepared by Lockheed Martin Hanford Corporation for Fluor Daniel Hanford, Inc., Richland, Washington.

RL, 1996, Project Hanford Management Contract (PHMC), DE-AC06-96RL13200, U.S. Department of Energy, Richland Operations Office, Richland, Washington.

RL, 1996, Privatization Contractor Phase 1 Contracts, DE-AC-96RL13308 and DE-AC96RL13309, U.S. Department of Energy, Richland Operations Office, Richland, Washington.

Shade, J.W., 1997, HNF-1517, Tank Waste Remediation System Retrieval and Disposal Mission Immobilized Low-Activity Waste Disposal Plan, prepared by Lockheed Martin Hanford Corporation for Fluor Daniel Hanford, Inc., Richland, Washington.

Treat, R. L., P. Bartley, T. J. McLaughlin, R. D. Potter, R. E. Raymond, and W. L. Willis, 1998, Tank Waste Remediation System Retrieval and Disposal Mission Technical Baseline Summary Description, HNF-1901, Rev. 0, prepared by Lockheed Martin Hanford Corporation for Fluor Daniel Hanford, Inc., Richland, Washington.

Vann, J.M., 1997, Tank Waste Remediation System Configuration Management Requiremetns Source Document, HNF-SD-WM-CM-016, Rev. 0, prepared by Lockheed Martin Hanford Corporation for Fluor Daniel Hanford, Inc., Richland, Washington. 
HNF-SD-WM-CM-014, Rev. 2

This page intentionally left blank. 


\section{Appendix A. TWRS CM Program Implementation Logic Network}

The following paragraphs and Figure A-1 describe the tasks that will be performed by the TWRS CM group and TWRS Programs to implement CM. Refer to Section 3.0 within the main body of this CMIP for a summary, responsibilities, source requirements, and objectives. Important milestones, the responsible programs, and the relationships of the tasks are identified in the figures. Specific dates, schedules, resources, and costs will be included and updated in the TWRS fiscal year planning.

\subsection{TWRS CM PROGRAM MANAGEMENT}

In accordance with the requirements of the PHMC CM Plan, the TWRS CM program management mechanisms have been established and will be used to provide a basis for improving the change control, configuration identification, configuration status accounting, and configuration assessment. The TWRS CM program management mechanisms will also be used to coordinate CM implementation across TWRS. The TWRS CM program management mechanisms are described in the TWRS CM Plan and its referenced procedures. The following are three of the primary tasks that have been completed. These tasks are shown on Figure A-1 on page A-21.

\subsection{APPOINT TWRS CM MANAGER}

This task has been completed. Responsibility for managing program development and maintenance and coordination of implementation actions was assigned to the manager of the TWRS CM group. The TWRS CM group is an organization within TWRS Technical Operations and Engineering. The job description and performance objectives for the TWRS CM Manager will be updated to include this responsibility.

\subsection{DEFINE TWRS CM PROGRAM}

This task has been completed. The TWRS CM program is defined in HNF-1900, which will be updated as necessary to comply with CM requirements and to incorporate TWRS CM program enhancements and process improvements.

\subsection{IDENTIFY PROGRAM PARTICIPANTS}

This task has been completed. All TWRS Programs will participate in the implementation of the TWRS CM program and in the improvement of that implementation. Each TWRS CM Program has an assigned $\mathrm{CM}$ representative. The job descriptions and performance objectives for these personnel will be updated to include this responsibility. 


\subsection{CHANGE CONTROL ENHANCEMENT}

The TWRS programmatic change control process has been updated by the TWRS Change Control Administrator. That process is being maintained consistent with the PHMC programmatic change control process and the TWRS technical change control process. The technical change control processes are being evaluated and enhanced via the following tasks.

Technical change control is being enhanced by the TWRS Requirements Engineering Technical Change Control Team. Where related enhancements to programmatic change control are necessary, the TWRS Change Control Administrator will participate to provide input and consensus with the decisions of the team. The Technical Change Control Implementation Plan will provide more detail regarding technical change control enhancements and related configuration status accounting enhancements. That plan will be issued later this year. The plan will include tasks' descriptions, responsibilities, and dates. Change control enhancement tasks are being performed in coordination with the HANDI 2000 effort. Enhancement of the change control will be made by implementing an improved change control system, procedures, and training.

\subsection{CHANGE CONTROL SYSTEM IMPROVEMENTS}

Improvements will be made to the change control process and the information systems used to perform change control. These improvements will be coordinated with the improvement and implementation of change control procedures and training, configuration status accounting enhancements, and configuration identification improvements.

\subsubsection{Develop Change Control System Criteria}

Change control system criteria have been developed and are contained in HNF-1900 and its referenced procedures. The TWRS Requirement Engineering Technical Change Control Team has refined the criteria based on the requirements prescribed in HNF-1900, interfacing requirements, and an evaluation of user needs. The updated criteria will be defined in and implemented in accordance with the Technical Change Control Implementation Plan.

\subsubsection{Evaluate Existing Change Control System Capabilities}

This task has been completed. This task identified the deficiencies within the change control process that impede the ability of TWRS to generate, control, and implement changes to the integrated TWRS baseline. Evaluation results are contained in the draft Technical Change Control Implementation Plan. These results provided bases for developing change control enhancements and planning their implementation. 
HNF-SD-WM-CM-014, Rev. 2

Appendix A. TWRS CM Program Implementation Logic Network

\subsubsection{Identify Change Control System Deficiencies}

This task has been completed. The deficiencies and recommended solutions are described in the draft of TWR-2411.

\subsubsection{Implement Near-term Change Control System Improvements}

Improvements that are needed to control changes to the configuration item and configuration information lists and other types of improvements that are needed or possible to make within a short time period will be identified for near-term implementation. Details regarding these improvements will be included in and implemented in accordance with TWR2411.

\subsubsection{Mitigate Long-term Change Control System Deficiencies}

The TWRS Requirements Engineering Technical Change Control Team has developed a technical change control process that will mitigate the deficiencies found in the existing change control system (engineering, operations, maintenance, and projects). Implementation of the new technical change control process will be performed via changes to the information management systems and change control procedures. Related implementation tasks will be documented in TWR-2411.

\subsubsection{Enable Enhanced Change Control System}

The enhanced change control system is needed to facilitate the use, maintenance, control, and correction of configuration information. The new technical change control process will be implemented in accordance with TWRS-2411. Implementation of the new process will be made via the coordinated issuance of procedures, procedure changes, training, and switching to the use of the enabling information system.

\subsection{CHANGE CONTROL PROCEDURE IMPROVEMENTS}

Improvements will be made to the procedures used to perform change control. These improvements will be coordinated with the improvement and implementation of change control systems and training.

\subsubsection{Identify Change Control Procedure Requirements}

As the new technical change control system is being developed, change control procedure requirements will be identified by the TWRS Requirements Engineering Technical Change Control Team and included in TWR-2411. These requirements will be based on the change control system criteria, deficiency resolutions, and user needs. These requirements will flow down to the implementing procedures. 


\subsubsection{Review Existing Change Control Procedures}

Existing change control procedures will be reviewed to determine how to change, supersede, cancel, or newly issue them to implement the new technical change control process.

\subsubsection{Identify Additional Change Control Procedure Needs}

The set of procedure related actions will be examined to identify those that are necessary to mitigate near-term change control system deficiencies. These near-term procedure actions will be identified and included in the Technical Change Control Implementation Plan. Procedure actions that will be performed later to implement the technical change control process will also be identified and included in the Technical Change Control Implementation Plan

\subsubsection{Develop Additional Near-term Change Control Procedures}

Based on the above analysis, procedure changes, cancellations, supersedure, and/or new procedures will be developed and issued. Procedure issuance will be coordinated with the implementation of other near-term change control enhancements.

\subsection{CHANGE CONTROL TRAINING IMPROVEMENTS}

Improvements will be made to change control training to support communication of the new change control mechanisms (e.g., change control process, information systems, procedures). Training improvements. will be coordinated with the improvement and implementation of change control systems and procedures.

\subsubsection{Identify Change Control Training Requirements}

As the technical change control system and procedures are being developed, related training requirements will be identified. Identification of training requirements will be specific to the change control function that personnel are to perform.

\subsubsection{Review Existing Change Control Training Capabilities}

An evaluation of the training practices for the various change control processes will be performed to identify existing training capabilities. This information will be used for the identification of change control training needs and ways to meet those needs.

\subsubsection{Identify Additional Change Control Training Needs}

Information from evaluation of the existing change control training capabilities, near-term change control needs, and planned actions to mitigate near-term change control system deficiencies will be used to identify the required near-term training. This training will be 
identified and included in TWR-2411. The training that will be performed for long-term implementation of the new technical change control process will also be identified and included in TWR-2411.

\subsubsection{Develop Additional Near-term Change Control Training}

Using the above information, training will be developed and implemented to support near-term change control system mitigation actions and the issuance of related procedures and procedure changes.

\subsubsection{Complete Near-term Change Control Training}

Near-term change control training needs to be completed to enable the control of the consolidated configuration item list and the development and control of the configuration item/configuration information list. This training will be coordinated with near-term procedure, change control process, and information system improvements.

\subsubsection{Revise Change Control Training to Include Procedure Changes}

The change control training will be updated to include the procedure changes that will be performed to complete implementation of the new technical change control process.

\subsubsection{Mitigate Long-term Change Control Training Deficiencies}

Based on the evaluation of the change control training capabilities and technical change control implementation planning, the remaining change control training deficiencies will be identified and included in TWR-2411 for long-term mitigation.

\subsubsection{Complete Enhanced Change Control System Training}

Sufficient personnel will be trained to enable implementation of the new technical change control process and any enhancements made to the programmatic change control process.

\subsection{CONFIGURATION STATUS ACCOUNTING ENHANCEMENT}

The configuration status accounting system is being enhanced to improve the control and retrievability of configuration information. This is being performed via improvements to the configuration status accounting system, procedures, and training. These are primarily addressed by the Configuration Management Information System project, which is documented in HNF-SD-TWR-CSWD-001. The project is being coordinated with the HANDI 2000 effort, improvement of the Hanford Document Control System and Records Management Information System, and similar information system efforts. Enhancement of configuration status accounting is being accomplished by evaluating the existing systems, identifying problems and areas for 
HNF-SD-WM-CM-014, Rev. 2

Appendix A. TWRS CM Program Implementation Logic Network

improvement, and implementing system changes. This includes improvement to the correlation and statusing of configuration information contained within the configuration status accounting system.

\subsection{CONFIGURATION STATUS ACCOUNTING SYSTEM IMPROVEMENTS}

\subsubsection{Develop Configuration Status Accounting Criteria}

The configuration status accounting criteria have been developed. The criteria are included in the TWRS CM Plan, its referenced procedures, and HNF-SD-TWR=CSWD-001. The configuration criteria are being refined to enhance configuration status accounting. Refinements are concentrating on the set of criteria used to manage configuration documentation and images and enable electronic work flow for developing and changing configuration documentation. Criteria changes are based on requirements defined in the TWRS CM Plan, interfacing systems and processes, and an evaluation of user needs.

\subsubsection{Evaluate Existing Configuration Status Accounting Capabilities}

This task has been completed. The task evaluated the capabilities of the existing systems used for configuration status accounting to determine the purpose, functioning, and capabilities of each system and how well the full set of systems satisfies the configuration status accounting criteria. Evaluation results are contained in HNF-SD-TWR-CSWD-001. The results of the evaluation provided bases for developing configuration status accounting enhancements and planning their implementation.

\subsubsection{Identify Configuration Status Accounting Deficiencies}

This task has been completed. Evaluation results are contained in HNF-SD-TWR-CSWD-001. Based on the above evaluation, the strengths and deficiencies of each system was identified as was their combined strengths and deficiencies. How well the full set of systems met duplicate configuration status accounting criteria and the results of the evaluation provided bases for developing configuration status accounting enhancements and planning their implementation.

\subsubsection{Mitigate Near-term Configuration Status Accounting Deficiencies}

Deficiencies that must be mitigated to enable the identification of configuration items and configuration information will be mitigated in the near term. The relationship to configuration identification improvement is reflected in Figure A-1. Where possible, other deficiencies may also be mitigated in the near-term. An important factor in mitigating near-term deficiencies will be acquiring the necessary $\mathrm{CM}$ Information System capabilities (see Figure A-1). Deficiencies and mitigation actions will be included in HNF-SD-TWR-CSWD-001. 
HNF-SD-WM-CM-014, Rev. 2

Appendix A. TWRS CM Program Implementation Logic Network

\subsubsection{Mitigate Long-term Configuration Status Accounting Deficiencies}

An enhanced configuration status accounting system is being developed. Deficiencies that cannot be mitigated in the near term will be identified for mitigation via implementation of that system. These deficiencies and their mitigation will be identified in the HNF-SD-TWR-CSWD-001.

\subsubsection{Enable Enhanced Configuration Status Accounting System}

The enhanced configuration status accounting system will be enabled into a manner that is timely to enable the gathering, evaluation, and correction of configuration information. The ability to implement the enhanced configuration status accounting system depends on the existence of the appropriate procedures and accomplishment training. Figure A-1 reflects that interdependence.

\subsection{IMPROVE CONFIGURATION STATUS ACCOUNTING PROCEDURES}

\subsubsection{Identify Configuration Status Accounting Procedure Requirements}

The requirements that need to be included in configuration status accounting procedures will be identified. These requirements will be based on the configuration status accounting criteria defined and the TWRS CM Plan and reference to procedures, as well as the criteria identified during the technical change.

\subsubsection{Review Existing Configuration Status Accounting Procedures}

Existing procedures will be evaluated against the configuration status accounting procedure requirements. This review will identify deficiencies in the procedure's ability to implement configuration status accounting requirements. Necessary procedure changes will be identified.

\subsubsection{Identify Additional Configuration Status Accounting Procedure Needs}

Based on the above evaluation, the need for additional configuration status accounting procedures will be identified. The set of procedure related actions will be examined to identify those that are necessary to mitigate near-term deficiencies. These near-term procedure actions will be identified and included in TWR-2411 and/or HNF-SD-TWR-CSWD-001. Procedure actions that will be performed later as part of long-term mitigation will also be identified and included in HNF-2411 and/or HNF-SD-TWR-CSWD-001. 
HNF-SD-WM-CM-014, Rev. 2

Appendix A. TWRS CM Program Implementation Logic Network

\subsubsection{Develop Additional Configuration Status Accounting Near-Term Procedures}

Configuration status accounting procedures and procedure changes that are necessary to mitigate near-term configuration status accounting deficiencies will be developed. The need for other procedural action will be identified in HNF-2411 and/or HNF-SD-TWR-CSWD-001.

\subsubsection{Mitigate Long-term Configuration Status Accounting Procedure Deficiencies}

Remaining configuration status accounting procedure needs and deficiencies will be resolved by showing the necessary procedures and procedure changes. This will be performed in accordance with HNF-2411 and HNF-SD-TWR-CSWD-001 and in conjunction with training to the new and revised procedures.

\subsection{IMPROVE AND PERFORM CONEIGURATION STATUS ACCOUNTING TRAINING}

\subsubsection{Identify Configuration Status Accounting Training Requirements}

Configuration status accounting training requirements necessary to support the use of new and revised procedures will be identified and included in HNF-2411 and/or HNF-SD-TWR-

CSWD-001, as appropriate.

\subsubsection{Review Existing Configuration Status Accounting Training Capabilities}

Existing training will be reviewed to determine its capability to provide the necessary configuration status accounting training.

\subsubsection{Identify Additional Configuration Status Accounting Training Needs}

The need for additional configuration status accounting training needs will be based on the above review and configuration status accounting training requirements. Those needs that must be met in the near-term will be identified. Needs that can be met over for a longer period will also be identified.

\subsubsection{Develop Near-term Additional Configuration Status Accounting Training}

A training plan and material will be developed and implemented to meet the near-term configuration status accounting training needs.

\subsubsection{Complete Near-Term Configuration Status Accounting Training}

Configuration status accounting training will be provided to the personnel that will be selecting configuration items and information and to the personnel responsible for managing the 
HNF-SD-WM-CM-014, Rev. 2

\section{Appendix A. TWRS CM Program Implementation Logic Network}

configuration status accounting system. The training will be provided in a timely manner to the configuration selection effort. This relationship is shown on Figure A-1.

\subsubsection{Revise Configuration Status Accounting Training Program to Include Procedure Changes}

The configuration status accounting training program will be updated to address progress in the issuance of new and revised configuration status accounting procedures.

\subsubsection{Complete Enhanced Configuration Status Accounting System Training}

Configuration status accounting training will be provided to the personnel that will be evaluating and correcting configuration information and to the personnel responsible for managing the configuration status accounting system. The training will be provided in a timely manner to those affected. This relationship is shown on Figure A-1.

\subsection{IMPROVE CONFIGURATION MANAGEMENT INFORMATION SYSTEMS}

Improvement of the $\mathrm{CM}$ information systems is essential to enabling the identification, control, maintenance, and use of the configuration baseline. These improvements are also a necessary part of implementing change control and configuration status accounting enhancements.

\subsubsection{Identify Configuration Management Information System Requirements}

This task is completed. In the configuration status accounting, criteria and requirements, and configuration status accounting deficiencies were used to determine Configuration Management Information System requirements.

\subsubsection{Review Existing Configuration Management Information System Capabilities}

This task is completed. The capabilities of the information systems that are included in the scope of the Configuration Management Information System effort have been evaluated and results included in the HNF-SD-TWR-CSWD-001. This will be updated as changes are made to related information systems.

\subsubsection{Identify Additional Configuration Management Information System Needs}

This task being performed in accordance with HNF-SD-TWR-CSWD-001. Based on the above evaluation, TWRS has identified where additional functionality is necessary. Due to the rapidly changing nature of the related information systems these needs are being re-validated. 
HNF-SD-WM-CM-014, Rev. 2

Appendix A. TWRS CM Program Implementation Logic Network

\subsubsection{Acquire Additional Near-Term Configuration Management Information System Capability}

Additional Configuration Management Information System capabilities that are needed to enable the configuration information selection process will be acquired. This will be accomplished by improving existing information systems and/or procuring new information systems. Planning for this will be included in HNF-SD-TWR-CSWD-001.

\subsubsection{Acquire Additional Long-Term Configuration Management Information System Capability}

The additional Configuration Management Information System capabilities that are required to implement a full and integrated configuration status accounting system will be acquired as defined in the HNF-SD-TWR-CSWD-001. This will be accomplished by improving existing information systems and procuring new information systems, if those new systems or not procured in the prior step.

\subsubsection{Perform Configuration Management Information System Test and Evaluation}

The Configuration Management Information System will be tested and evaluated to ensure that it is sufficient to establish the enhanced configuration status accounting system.

\subsubsection{Implement Enhanced Configuration Management Information System}

Implementation of the enhanced Configuration Management Information System will essentially enable the enhanced configuration status accounting system. The Configuration Management Information System effort provides the information system infrastructure and architecture necessary to enhance the configuration status accounting system.

\subsection{CONFIGURATION IDENTIFICATION IMPROVEMENT}

Improvement to configuration identification will be accomplished by improving the process, procedures, and training used for configuration identification; selecting configuration items; selecting configuration information; and evaluating and improving the configuration information.

As shown by Figure A-1, the ability to implement or improve configuration identification depends on the maturity of change control and configuration status accounting. 
HNF-SD-WM-CM-014, Rev. 2

Appendix A. TWRS CM Program Implementation Logic Network

\subsection{CONFIGURATION IDENTIFICATION PROCESS IMPROVEMENT}

The process for selecting and identifying configuration items and information will be evaluated and improved in conjunction with improvement of configuration identification procedures and training.

\subsubsection{Develop Configuration Identification Process Criteria}

The configuration identification process criteria in the TWRS CM plan and referenced procedures. The configuration identification criteria necessary to perform configuration status accounting enhancement, change control enhancement, and configuration identification improvements are being updated and will be included in CM procedures. An example of this enhancement is the criteria that are being developed to define the process for identifying and selecting configuration items and configuration information. An evaluation will be made regarding the need for configuration identification criteria to support the verification and validation of configuration information. If needed, such criteria will be developed and included in the CM procedures.

\subsubsection{Perform Program Review of Configuration Identification Process Criteria}

As CM procedures and revisions are prepared they will be reviewed by the TWRS Programs to ensure that they include the configuration identification process criteria and are sufficient for use by the TWRS Programs.

\subsubsection{Incorporate Program Comments into Configuration Identification Process Criteria}

Comments resulting from review of the $\mathrm{CM}$ procedures and configuration identification process criteria will be dispositioned and appropriately incorporated into those criteria.

\subsubsection{Obtain Approval of Configuration Identification Process Criteria}

Procedures containing the revised configuration identification process criteria will be submitted to the TWRS Chief Engineer for approval.

\subsubsection{Issue Configuration Identification CM Process Criteria}

Procedures containing the configuration identification process criteria will be issued in a timely manner to enable personnel to be trained to those procedures sufficiently to enable the proper implementation of the procedures and underlying requirements. 
Appendix A. TWRS CM Program Implementation Logic Network

\subsubsection{Develop CM Selection Criteria}

This task has been completed. CM selection criteria are contained within the draft TWRS CM procedure. Development of the CM selection criteria was part of improving the configuration identification process.

\subsubsection{Perform Program Review of Selection Criteria}

This step has been completed. The TWRS Programs reviewed the configuration item selection criteria to ensure it contains the appropriate criteria that will provide for control of items and information that will be needed to accomplish the program's mission. Comments were provided to the TWRS CM group.

\subsubsection{Incorporate Program Review Comments into Selection Criteria}

Upon completion of the review, comments will be dispositioned and appropriately incorporated into the $\mathrm{CM}$ selection criteria.

\subsubsection{Perform LMHC Senior Management Review of Selection Criteria}

The final draft of the CM selection criteria will be reviewed by LMHC senior management. This review is necessary to ensure that the $\mathrm{CM}$ selection criteria are sufficient to meet the requirements of the LMHC senior management. Comments will be submitted to and dispositioned by the TWRS CM group. The revise criteria will be included in the TWRS CM procedure.

\subsubsection{Obtained LMHC Senior Management Approval of CM Selection Criteria}

The TWRS CM group will obtain the appropriate approval(s) of the TWRS CM procedure(s) that contain the $\mathrm{CM}$ selection criteria.

\subsubsection{Issue CM Selection Criteria}

The CM selection criteria will be issued as part of the TWRS CM selection procedure(s).

\subsection{IMPROVE CM SELECTION PROCEDURES.}

Procedures used for selecting TWRS configuration items and information will be updated to include CM process and CM selection criteria improvements. Development and issuance of the improved procedures will be coordinated with other CM Program improvement and implementation activities and with training relevant to the new/revised $\mathrm{CM}$ selection procedures. 
Appendix A. TWRS CM Program Implementation Logic Network

\subsubsection{Identify Selection Procedure Requirements}

The selection procedure requirements will include the $\mathrm{CM}$ selection criteria, $\mathrm{CM}$ selection process criteria, and any other criteria needed to enable the configuration item and configuration information selection process.

\subsubsection{Review Existing Selection Procedures}

The existing selection procedures will be identified and evaluated to determine whether they are sufficient to be used in selecting configuration items and configuration information.

\subsubsection{Identify Additional Selection Procedure Needs}

A determination will be made as to whether existing selection procedures should be revised or replaced. If selection procedures do not exist, the need to develop them will be identified.

\subsubsection{Develop Additional Selection Procedures}

Where necessary, selection procedures will be revised and/or new selection procedures will be developed to meet the identified needs. As noted above, the $\mathrm{CM}$ selection criteria will be issued as part of the TWRS CM selection procedure(s).

\subsubsection{Prepare Configuration Item List Development Guidelines}

Guidance to assist the TWRS Programs in development of their configuration item lists will be developed in conjunction with the development/revision of the selection procedures. This guidance may be included in a selection procedure or a separate procedure or issued as an electronic form.

\subsubsection{Perform Selection Procedure Test and Evaluation}

New and revised $\mathrm{CM}$ procedures will be tested prior to their implementation. The results of this testing will be evaluated to ensure the procedures are sufficient for implementation

\subsubsection{Implement Selection Procedures}

Issuance of selection procedures will be coordinated with related training. Procedures will be issued and distributed in a timely manner to facilitate the selection process. 
HNF-SD-WM-CM-014, Rev. 2

Appendix A. TWRS CM Program Implementation Logic Network

\subsection{IMPROVE AND IMPLEMENT CM SELECTION TRAINING}

Improvement and implementation of CM selection training will be coordinated with the development and implementation of an improved selection process and procedures.

\subsubsection{Identify Selection Training Requirements}

The criteria for selecting configuration items and information and the related procedures will be evaluated to identify the necessity, scope, and nature of training that is required to support the selection tasks.

\subsubsection{Review Existing Selection Training Capabilities}

The existing training for configuration item and information selection will be examined to determine the strengths and weaknesses of that training.

\subsubsection{Identify Additional Selection Training Needs}

Based on strengths and weaknesses identified by the above examination, configuration selection training needs will be identified.

\subsubsection{Develop Additional Selection Training}

A training plan and material will be developed to fulfill the configuration item and information selection training needs.

\subsubsection{Test and Evaluate Selection Training Program}

The selection training plan and material being tested and evaluated to ensure that is sufficient to meet the configuration selection training needs. Any insufficiencies will be identified in resolved.

\subsubsection{Implement Selection Training Program}

Sufficient personnel will be trained to enable the configuration selection process to begin. The training will be completed in a manner that is timely to the issuance of related $\mathrm{CM}$ procedures and CM system enhancements.

\subsection{SELECT CONFIGURATION ITEMS}

Each TWRS Program will identify the configuration items for which they are responsible and provide this information to the TWRS CM group. Since the basic tasks for each of the 
HNF-SD-WM-CM-014, Rev. 2

\section{Appendix A. TWRS CM Program Implementation Logic Network}

programs are the same, for brevity the general term "TWRS Program" or "Program" will be used in the following paragraphs in place of the titles of the specific programs.

\subsubsection{Identify Program's Candidate Items}

Using the configuration item selection criteria each TWRS Program will develop a list of items for which it is responsible. Items that the program needs but that are the responsibility of another program will be checked later in this process. Where a physical configuration item does not yet exist and is reflected only in information (e.g., a project that has defined the architecture at a system level) the program will identify the "virtual" configuration item at the level for which definition exists and consistent with the life-cycle of the configuration item. The purpose of identifying a virtual configuration item is to be able to tie associated information to it.

Where it is not possible to identify configuration items down to the level that work is being performed, items will be identified at the lowest level possible. The need for further configuration item identification will be listed as an issue. The necessary tasks to complete selection and identification of configuration items will be performed as part of near-term or longterm issue resolution.

\subsubsection{Evaluate Program's Candidate Items vs. Configuration Item Selection Criteria.}

Each TWRS Program will review its candidate item list and ensure it is consistent with the selection criteria. If the selection criteria are insufficient, the program will contact the TWRS CM organization.

\subsubsection{Select Program's Configuration Items.}

Each TWRS Program will finalize the program's configuration item list. The program will ensure the list includes the configuration items' status and information requested by the TWRS CM organization.

\subsubsection{Submit Program's Configuration Item List to TWRS CIM Group}

Each TWRS Program will submit the program's configuration item list to the TWRS CM organization by April 30, 1998.

\subsubsection{Review Configuration Item Lists for Compliance}

The TWRS CM group will review the configuration item lists provided by the TWRS Programs and ensure that the lists comply with the configuration item selection criteria. Any issues will be identified so that they can be resolved later in this process. 
HNF-SD-WM-CM-014, Rev. 2

Appendix A. TWRS CM Program Implementation Logic Network

\subsubsection{Review Configuration Item Lists for Duplications/Omissions}

The TWRS CM group will review the configuration item lists and identify any duplication and/or omission. Any issues will be identified so that they can be resolved later in this process.

\subsubsection{Resolve Issues Resulting from CM Review}

The TWRS CM group will work with the TWRS Programs to resolve any issues identified by the two preceding reviews.

\subsubsection{Develop Consolidated Configuration Item List}

The TWRS CM group will develop a consolidated list of TWRS configuration items. This list will be included in a system for tracking configuration identification progress.

\subsubsection{Validate Configuration Item Ownership}

The TWRS CM group will review the consolidated configuration item list and ensure that a responsible organization is identified for each configuration item. This information will be included in the system used for tracking configuration identification. The TWRS CM group will resolve any issues with the associated TWRS Program.

\subsubsection{Enter Configuration Item List into Configuration Status Accounting System}

The TWRS CM group will provide the TWRS configuration item list to the Document/Information Management Center (DIMC). The DIMC will update the configuration status accounting system to reflect this information.

\subsection{SELECT CONFIGURATION INFORMATION}

The TWRS configuration item list will be used to make any needed refinements to the configuration information selection criteria. The TWRS Programs will then identify and evaluate the information for which they are responsible.

\subsubsection{Prepare Configuration Information Development Guidelines}

The TWRS CM group will review the selection procedures and update the guidance for configuration information development. This guidance will be included in CM procedures and training will be conducted in a timely manner to enable the identification, gathering, and evaluation of configuration information. 
HNF-SD-WM-CM-014, Rev. 2

Appendix A. TWRS CM Program Implementation Logic Network

\subsubsection{Review Existing Program Configuration Information Criteria}

The intent of this step is to revalidate the configuration information selection criteria using the information learned during selection of configuration items. Each TWRS Program will review the configuration information selection criteria to ensure that it identifies sufficient configuration information to enable the program's mission and tasks. Issues will be resolved via the TWRS CM group.

\subsubsection{Review Existing Program Configuration Information}

Due to the amount of information that will be retrieved or acquired from vendors, the TWRS Programs will request the information from the records system and vendors via the DIMC. The DIMC will act as a single point of contact to coordinate this retrieval/acquisition. The DIMC will prevent duplicate retrievals/acquisitions, enter the information into the configuration status accounting system, and provide all TWRS Programs with access to the information.

Each TWRS Program will review the program's existing configuration information against the configuration information selection criteria. The program will prepare a list that identifies the configuration information for which it is responsible and is needed to support configuration items and/or the program's mission. Where it is not possible to evaluate information for selection in time to support this task, the need for the evaluation will be identified and addressed as part of the configuration information update (see Section 4.0).

Each TWRS Program will ensure the list includes the status information requested by the TWRS CM organization. The list will correlate the configuration information with the respective configuration item (per configuration item list). The configuration item will be identified at the level consistent with the level covered by the configuration information. A document that addresses an entire system or multiple components of a system should only be tied to that system or the subsystem that contains those components.

Information that is owned by others but that the program needs will be identified later in the process through a review of the consolidated configuration item/configuration information list. The program will provide a list of issues related to the configuration information criteria with the TWRS CM organization Iater in this process.

\subsubsection{Identify Additional Program Information Needs}

Configuration information needed by the program and that is not covered by the configuration information criteria will be identified. Each TWRS Program will provide a list of the program's configuration items and configuration information to the TWRS CM group. Any issues related to the configuration information criteria will also be identified to the TWRS CM group. 


\subsubsection{Develop Consolidated Configuration Item//nformation List}

The TWRS CM group will consolidate the TWRS Program's lists and submit the consolidated list to TWRS senior management for review and approval. Once approved, this is the list of items and information that will be configured and maintained.

\subsubsection{LMHC Senior Management Review Consolidated List}

TWRS senior management will review consolidated configuration item/information list so it is consistent with TWRS mission needs. Open issues will be resolved.

\subsubsection{Incorporate LMHC Senior Management Review Comments into Consolidated List}

The TWRS CM organization will resolve issues and incorporate review comments into the consolidate configuration item/information list, as appropriate.

\subsubsection{Obtain LMHC Senior Management Approval of Consolidated List}

The TWRS CM organization will acquire senior management approval of the consolidated configuration item/information list. The TWRS CM group will submit the configuration item/information list to the DIMC, who will update the configuration status accounting system.

\subsubsection{TWRS Consolidated Configuration Item/Information List Complete}

The TWRS consolidated configuration item/information list will be complete by May 30 , 1998. Based on this list a review will be made of this list to determine whether changes to the planning of the following $\mathrm{CM}$ implementation tasks.

\subsubsection{Enter Configuration Item/Information List into Configuration Status Accounting}

The DIMC will issue the configuration item/information list and use it to update and correct the configuration status accounting system.

\subsubsection{Distribute Configuration Item/Information List}

The TWRS CM group will distribute the issued configuration item/information list to the TWRS Programs. This will be done in a timely manner to enable the next set of configuration identification improvement tasks. 


\subsection{UPDATE CONFIGURATION IDENTIFICATION}

The TWRS Programs will be provided with access to the Hanford Document Control System and Records Management Information System to facilitate this task. Each TWRS Program will establish the program's configuration baseline. Each program will identify issues and deficiencies and related resolutions. Where possible, issues and deficiencies will be resolved within the near-term. Otherwise, they will be included in the Program's CM implementation plan for long-term resolution.

\subsubsection{Perform File Search for Program's Configuration Information}

The TWRS Programs will request the information from the records system and vendors via the DIMC. The DIMC will act as a single point of contact to coordinate the retrieval and acquisition of information.

Each TWRS Program will review the available information sources and acquire the program's configuration information (in accordance with the configuration information list). The program will acquire configuration information that is readily available first. Configuration information that is more difficult to get will be acquired later in this process (planning will be updated to reflect the need to acquire that information). The program will identify the status of the configuration information, including whether it has been issued, is uncontrolled, or is in draft status.

\subsubsection{Correlate Program's Configuration Information with Configuration Item/Information List}

Each TWRS Program will identify the configuration item that is related to each set of configuration information. This will be consistent with the TWRS configuration item/information list. Changes to the list will be processed via the TWRS CM organization.

\subsubsection{Evaluate Adequacy of Program's Configuration Information}

Each TWRS Program will determine whether the configuration information listed is sufficient to support the program's configuration items and mission. Inadequacies in the configuration information will be identified and, if possible, resolved. Configuration information will be flagged as to whether it is sufficient or needs further action. The program will identify the type of additional information that is needed and any unresolved issues. Unresolved issues that need a long period of time to resolve will be included in the Program's CM implementation plan.

\subsubsection{Acquire Additional Program Configuration Information}

Each TWRS Program will acquire the missing configuration information that can be acquired within the time allotted for this task. The program will flag the configuration information as to whether it is sufficient or needs further action. Open issues with configuration 
HNF-SD-WM-CM-014, Rev. 2

Appendix A. TWRS CM Program Implementation Logic Network

information will also be resolved, when possible. Open issues and information that will take more time to acquire will be identified in the Program's CM implementation plan.

\subsubsection{Submit Program's Configuration Identification Package to TWRS CM Group}

Each TWRS Program will submit the program's configuration identification package to the TWRS CM organization. For configuration information that is contained in an approved configuration status accounting system and is deemed sufficient or is part of a long-term issue, only its status need be included in the package. This package should include corrected configuration information and configuration information that is not already contained in the approved configuration status accounting system. The TWRS CM organization and the DIMC will provide a list of configuration status accounting systems in time for the programs to accomplish this task.

\subsubsection{Review Program's Configuration Identification Package}

The TWRS CM organization will review the programs' configuration identification packages to ensure they are consistent with the TWRS configuration item/configuration information list. This task will require the support of each program.

\subsubsection{Incorporate Review Comments into Program's Configuration Identification Package}

Each TWRS Program will work with the TWRS CM organization to resolve any issues related to the program's configuration identification package.

\subsubsection{Submit Program's Configuration Identification Package to DIMC}

Once the issues within the package have been resolved and TWRS CM has signed concurrence, each TWRS Program will submit its configuration identification package to the DIMC. This task should be completed by April 30, 1999.

\subsubsection{Enter Configuration Identification Package into Configuration Status Accounting}

The DIMC will use the TWRS Programs' configuration identification packages to update configuration status accounting.

\subsubsection{Near-Term CM Implementation Improvements Complete}

At this point near-term $\mathrm{CM}$ implementation improvement is complete. Open issues have been identified within the TWRS Programs' CM implementation plans and are being tracked to completion of the associated resolutions. Ongoing implementation of $\mathrm{CM}$ will occur as part of each program's normal work activities and will be planned accordingly. 
HNF-SD-WM-CM-014, Rev. 2

Appendix A. TWRS CM Program Implementation Logic Network

\subsection{MITIGATE OPEN CONFIGURATION IDENTIFICATION ISSUES}

The following steps only need to be performed by programs whose configuration package included open issues. In such cases action plans are required to mitigate these long-term issues.

\subsubsection{Review Programs Configuration Identification Status}

Each applicable TWRS Program will review the status of the program's configuration items and configuration information to identify any inadequacies and open issues (see Section 4.6 above).

\subsubsection{Identify Long-term Program's Configuration Identification Issues}

Each applicable TWRS Program will develop a list of the long-term configuration information issues and respective resolutions. This list will be used to develop an action plan that will resolve those issues.

\subsubsection{Plan Mitigation of Long-term Issues}

Using the list of long-term configuration information issues and respective resolutions, each applicable TWRS Program will update or issue a CM implementation plan to include mitigation of those issues. The plan will include a schedule, responsible individuals, and funding source for mitigating actions. The program will ensure the plan is coordinated with other involved or impacted programs. The plan will be submitted to the TWRS CM organization for concurrence to be issued.

\subsubsection{Enter Programs' Revised CMIPs in Configuration Status Accounting}

The TWRS CM group will resolve any issues related to the programs' $\mathrm{CM}$ implementation plans with the programs. DIMC will enter each program's CM implementation plan into the configuration status accounting system.

\subsubsection{Implement Programs' CMIPs}

Each TWRS Program will track the actions listed in the Program's CM implementation plan to completion. Requested status will be provided to the TWRS CM group.

\subsubsection{Implementation Improvements Complete}

Upon completion and closure of the last mitigating action, long-term improvement of $\mathrm{CM}$ implementation is complete. Ongoing implementation of $\mathrm{CM}$ will occur as part normal work activities and will be planned accordingly. 
HNF-SD-WM-CM-014, Rev. 2

Appendix A. TWRS CM Program Implementation Logic Network

\subsection{ASSESSMENTS}

Assessments are necessary to evaluate and improve the effectiveness of the CM program, functional and physical capability of products, and testing. CM Assessments are being performed in a variety of manners as appropriate to evaluate existing processes and test enhancements and new processes. Since CM assessments are performed as part of the tasks to enhance and improve CM implementation, details for this activity are not reflected in Figure 2 or the Appendix. CM assessments will be used to evaluate the success of CM implementation.

\subsection{DEVELOP CM ASSESSMENT CRITERIA}

The TWRS CM assessment criteria have been developed. The criteria are included in the TWRS CM Plan and its referenced procedures. The TWRS Systems Engineering Technical Change Control Team has refined the change control criteria. The new criteria are based on the requirements defined in the TWRS CM Plan, interfacing systems and processes, and an evaluation of injured needs.

\subsection{IMPLEMENT CM ASSESSMENT WHILE ENHANCING CM}

As stated earlier, the teams involved in change control enhancement, configuration status account enhancement, and configuration identification improvement have further refined these criteria has been further refined to meet needs specific to their efforts. They confined effect of the effort to these teams isn't in-depth assessment of both the functioning of the configuration management program and its implementation as reflected in the configuration items and configuration information.

\subsection{IMPLEMENT ONGOING CM ASSESSMENTS}

As the configuration information baseline is established, a process for performing ongoing configuration management assessments will be developed. The process will be proceduralized and assessment actions will be included in fiscal year planning.

\subsection{IMPLEMENT SCHEDULED CM ASSESSMENTS}

Implementation of scheduled configuration management assessments depends on the existence of a well-defined configuration information baseline and $\mathrm{CM}$ system that can be assessed. This relationship is reflected in Figure A-1. Once the configuration information baseline is established, it will be assessed to identify configuration identification issues. Provision for resolution of those issues will be included as part of the CM assessment program and $\mathrm{CM}$ program management tasks. 


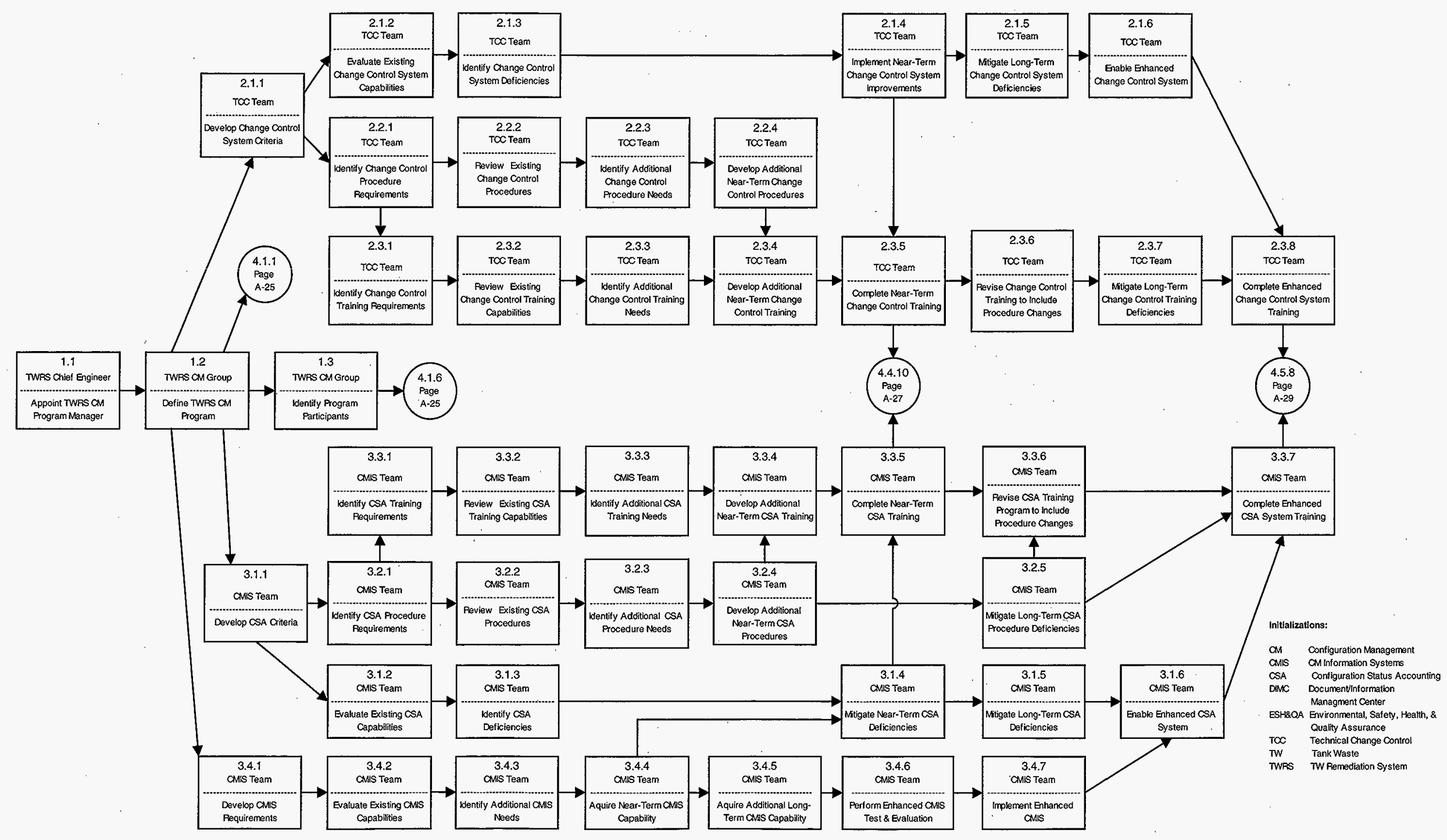




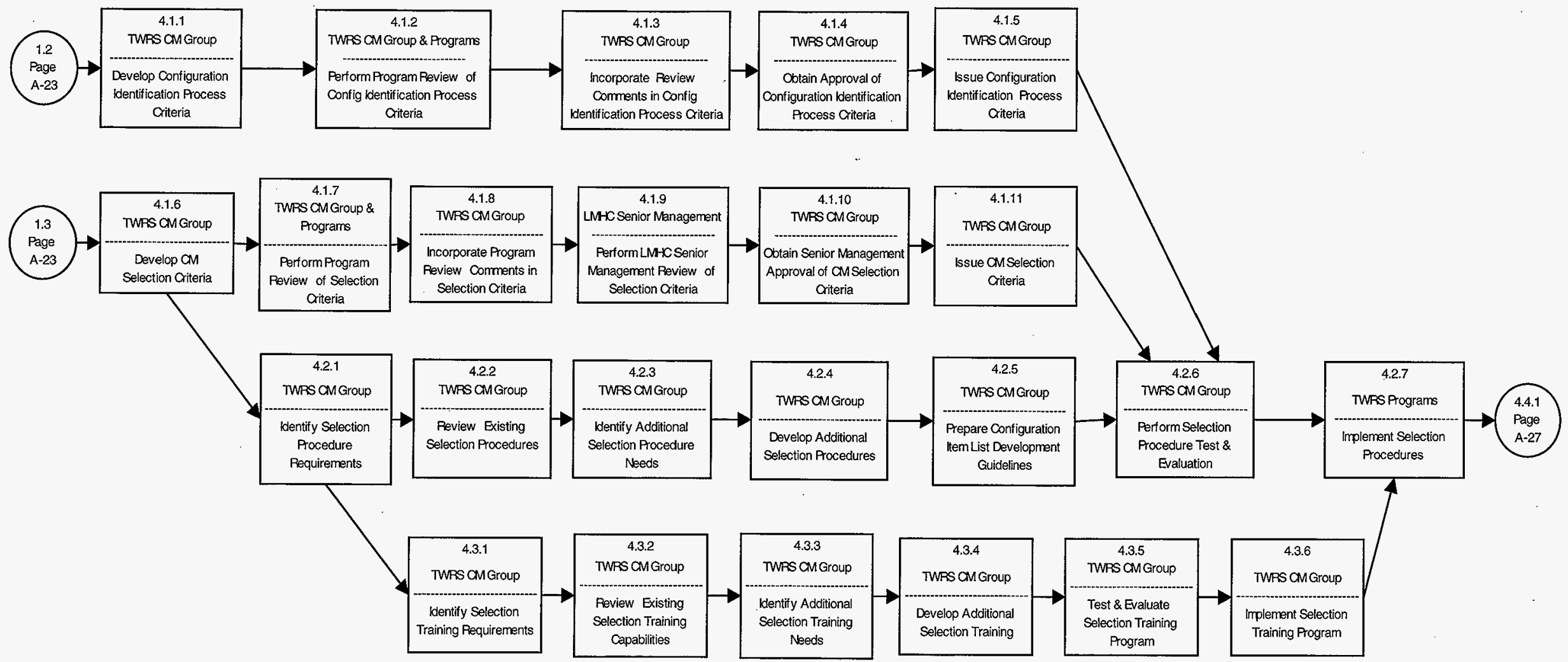




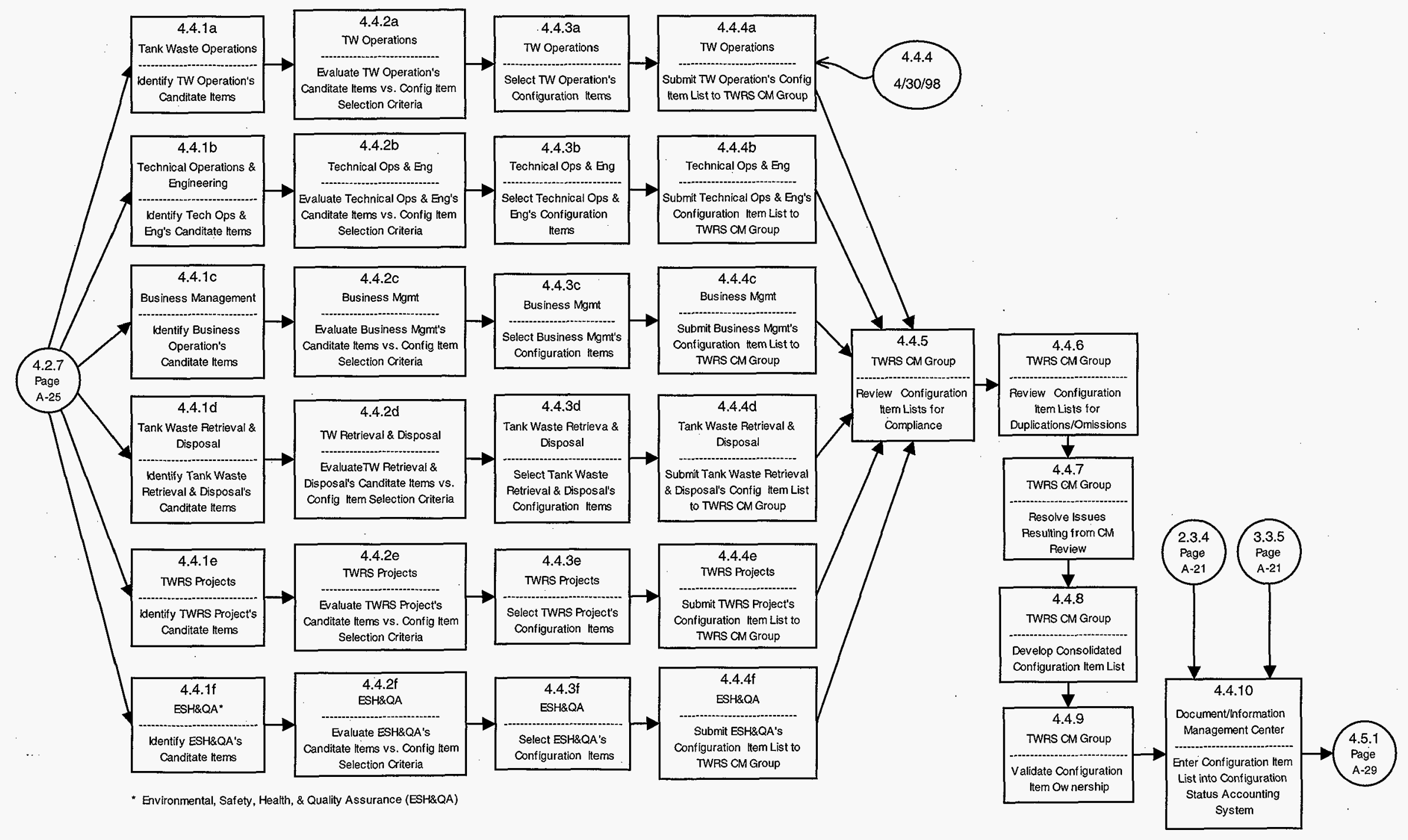


离

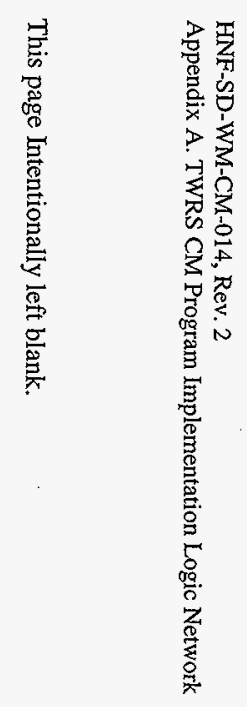


HNF-SD-WM-CM-014, Rev. 2 Appendix A. TWRS CM Program Implementation Logic Network Figure A-1. TWRS CM Program Implementation Logic Network

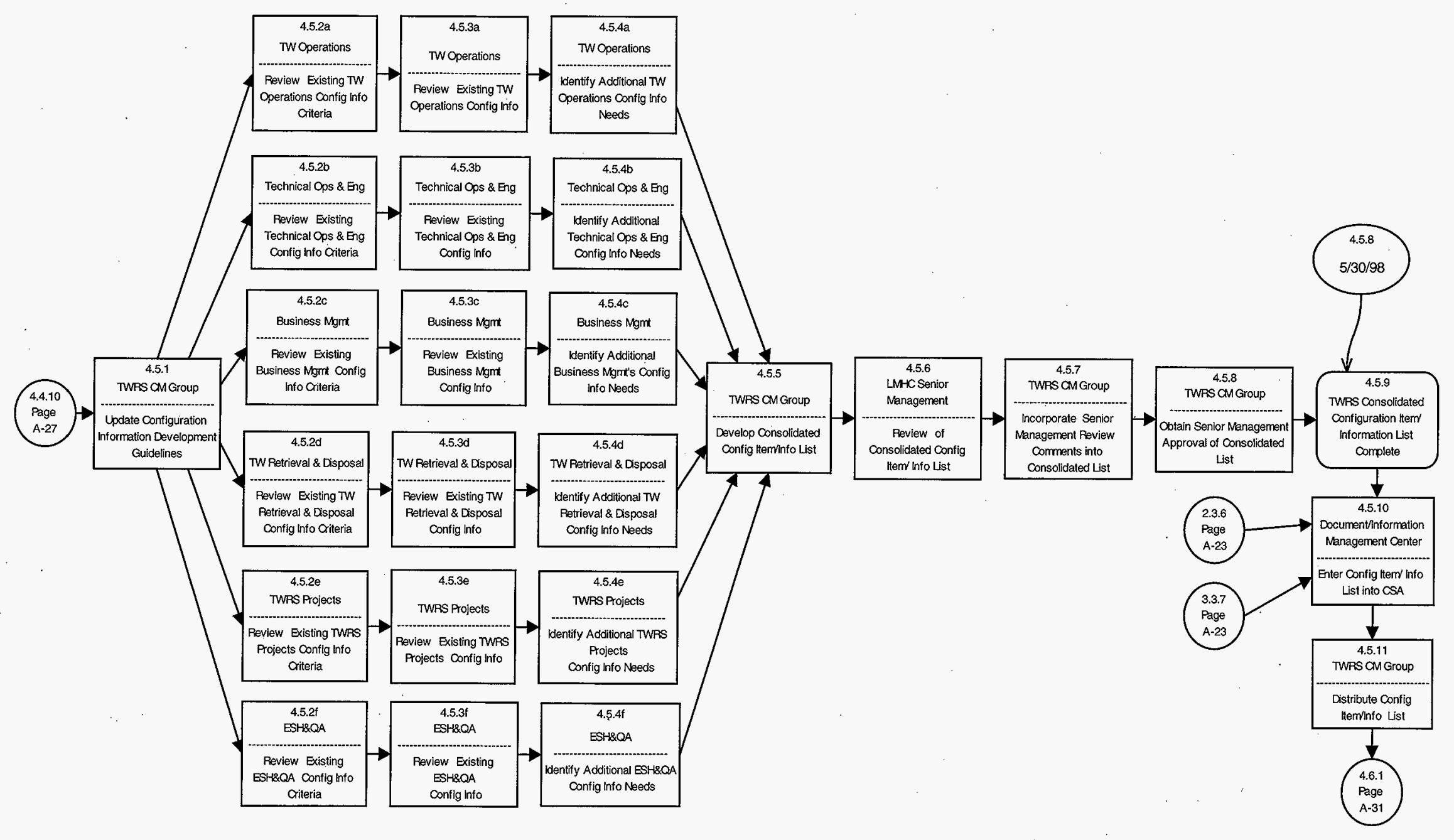


离

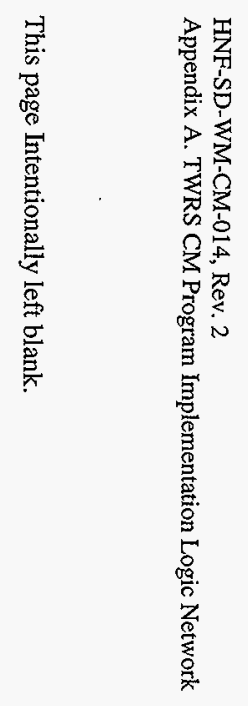



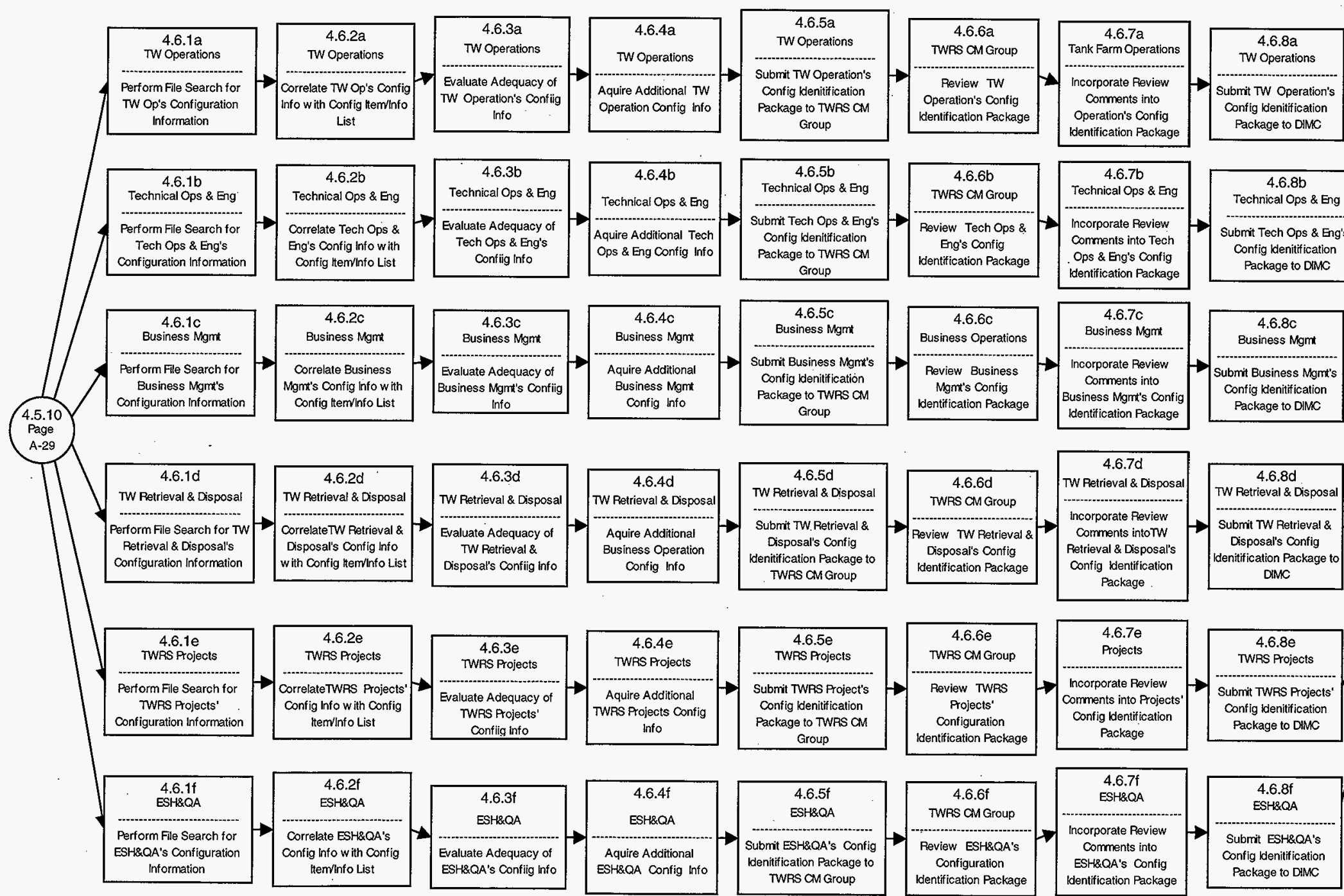

Identification Package
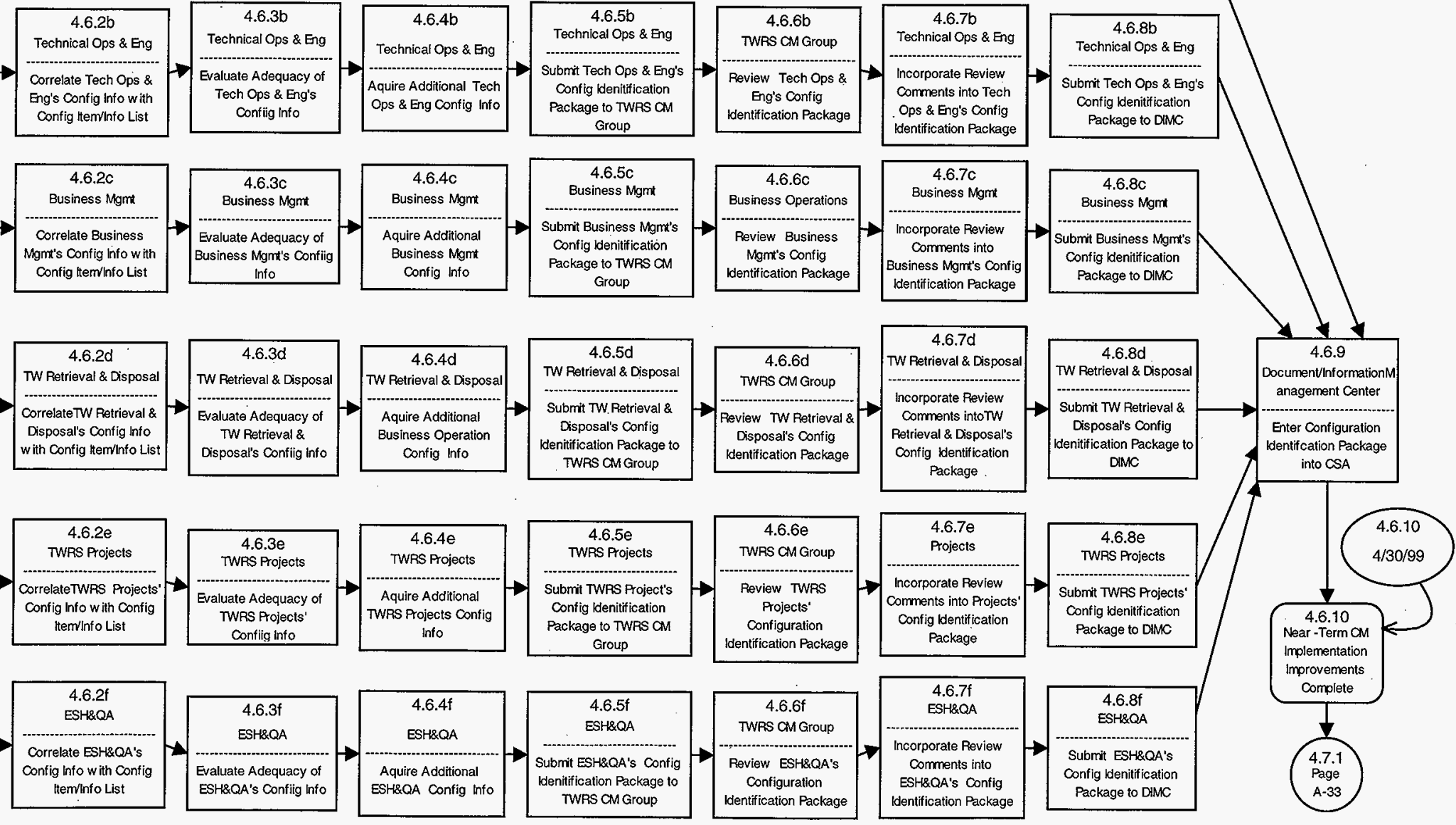
NNF-SD-WM-CM-014, Rev. 2

Appendix A. TWRS CM Program Implementation Logic Network

This page Intentionally left blank 


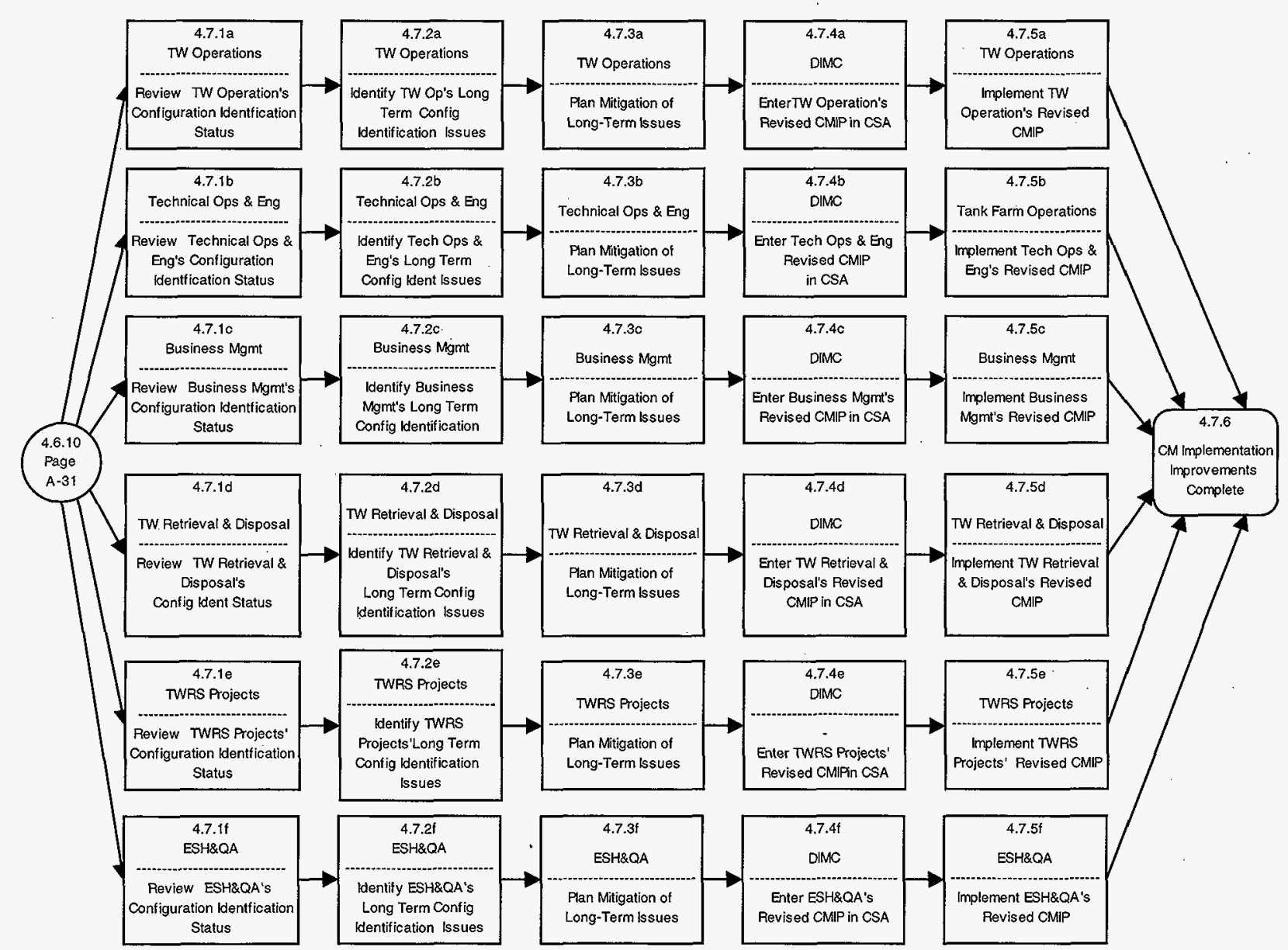


HNF-SD-WM-CM-014, Rev. 2

Appendix A. TWRS CM Program Implementation Logic Network

This page Intentionally left blank. 